\title{
Development of a Gaussian Process Model as a Surrogate to Study Load Bridging Performance in Racked Pallets
}

\author{
Eduardo Molina (D) and Laszlo Horvath * (D) \\ Department of Sustainable Biomaterials, Virginia Polytechnic Institute and State University, 1650 Research \\ Center Drive, Blacksburg, VA 24061, USA; molina@vt.edu \\ * Correspondence: lhorvat@vt.edu; Tel.: +1-540-231-7673
}

Citation: Molina, E.; Horvath, L. Development of a Gaussian Process Model as a Surrogate to Study Load Bridging Performance in Racked Pallets. Appl. Sci. 2021, 11, 11865. https://doi.org/10.3390/ app112411865

Received: 22 September 2021 Accepted: 9 December 2021 Published: 14 December 2021

Publisher's Note: MDPI stays neutral with regard to jurisdictional claims in published maps and institutional affiliations.

Copyright: (c) 2021 by the authors. Licensee MDPI, Basel, Switzerland. This article is an open access article distributed under the terms and conditions of the Creative Commons Attribution (CC BY) license (https:// creativecommons.org/licenses/by/ $4.0 /)$.

\begin{abstract}
Current pallet design methodology frequently underestimates the load capacity of the pallet by assuming the payload is uniformly distributed and flexible. By considering the effect of payload characteristics and their interactions during pallet design, the structure of pallets can be optimized and raw material consumption reduced. The objective of this study was to develop a full description of how such payload characteristics affect load bridging on unit loads of stacked corrugated boxes on warehouse racking support. To achieve this goal, the authors expanded on a previously developed finite element model of a simplified unit load segment and conducted a study to screen for the significant factors and interactions. Subsequently, a Gaussian process (GP) regression model was developed to efficiently and accurately replicate the simulation model. Using this GP model, a quantification of the effects and interactions of all the identified significant factors was provided. With this information, packaging designers and researchers can engineer unit loads that consider the effect of the relevant design variables and their impact on pallet performance. Such a model has not been previously developed and can potentially reduce packaging materials' costs.
\end{abstract}

Keywords: packaging; optimization; Gaussian process; finite element; load bridging; pallets

\section{Introduction}

With more than 6.8 billion pallets in circulation around the world [1] and over $80 \%$ of the current shipping volume utilizing some form of corrugated fiberboard packaging [2], it is critical to optimize pallet and packaging design. Previous research has shown that the performance of corrugated boxes is affected by the characteristics of the pallet that supports them, including factors such as deck board stiffness, gaps between the boards, unsupported box corners, among others [3-6]. Additionally, pallet performance is affected by the type of storage and material handling equipment used. An extensive body of knowledge has been developed to understand pallet performance for the most common supply chain environments, for different pallet materials, and for other design characteristics [7-10]. Research studies have been conducted to evaluate the pallet performance when unit loads are supported on conditions such as warehouse racking across the length, across the width, supported on forklift tines, or stacked on the floor [11-13].

Research has also been conducted to understand how the characteristics of the payload affects the performance of pallets. This research has commonly shown that when a pallet carries a more rigid payload, the pallet's deformation decreases. This behavior is known as the load bridging effect and entails the redistribution of the compressive forces towards the rigid supports and away from the critical pallet components that might be more susceptive to failure $[14,15]$. To characterize this effect, studies were conducted evaluating specific factors that could potentially influence the load bridging effect. Factors such as the dimensions of the packages, their contents, package stacking patterns, number of layers of packages, total height of the unit load, and load containment methods have all been evaluated $[12-14,16,17]$. This research has historically been conducted through physical experimentation with limited evaluation of the potential interactions between these factors. 
The load bridging effect has been measured through the change in the overall deformation of the pallet structure and by evaluating the changes in the pressure distribution across the pallet top decks $[11,12,16,18]$.

Physical experimentation for large systems, such as pallets carrying multiple packages, presents low repeatability due to the potential variation in uncontrollable factors. To account for this, simplified general models have been developed. Han et al. [19] developed a finite element model to predict the deformation of pallet top deck boards under nonuniform load applications, but this only has limited application to rigid loads. Molina, Horvath, and West [20] presented a model simulating the bending behavior of a simplified unit load segment using an implicit dynamic, two-dimensional finite element analysis approach. Unlike previous approaches, this model provides a method to generically analyze a unit load when stored on warehouse rack beam support in order to determine the predicted level of load bridging for the specific load characteristics. Seven different unit load characteristics were identified as potentially influencing the magnitude of the load bridging effect. These were: payload weight, friction between the pallet and the packages, friction between packages, box dimensions represented as the number of columns and number of layers, overall height of the unit load, and the stiffness of the pallet.

Although the developed finite element model represents a robust baseline to use in studying the characteristics of a unit load and their influence on pallet performance, a full analysis of the trends and interactions of all the identified factors increases the computing requirements exponentially. A surrogate model of a complex finite element model is commonly utilized in such scenarios, providing not only a more efficient analysis tool but also an accessible method for industry practitioners to design unit loads using acceptable approximations [21-27].

Being able to better understand the effects of the payload's characteristics that influence the load bridging effect can allow for an improved design methodology for unit loads. Designers would be better able to identify the critical factors of unit loads that might be negatively impacting pallet performance. A complete, comprehensive knowledge of the load bridging effect factors is not currently available. This paper continues the research based on the model developed by Molina, Horvath, and West [20].

\section{Objectives}

The main objective of this investigation was to characterize the effects, significant factors, and interactions influencing load bridging on unit loads. This will provide a clear understanding of the load bridging effect and how it can be successfully applied during the unit load design process.

To attain the main objective of this project, specific objectives are defined as follows:

1. To evaluate the significance of the seven identified factors and their interactions that influence load bridging for unit loads of stacked corrugated boxes on warehouse racking support.

2. To develop and validate a Gaussian process regression model that can efficiently and accurately replicate the finite element simulations.

3. To quantify and describe the effect of all identified significant load bridging factors influencing pallet bending, as well as the interactions between them.

\section{Materials and Methods}

This research was structured to be presented in three main sections. First, a fractional factorial screening design was conducted to identify the significance of multiple factors that could have an influence on the load bridging effect on racked unit loads. Second, a Gaussian process model was developed, as a surrogate model, to increase the efficiency of the analysis and the potential of its application. In the third and final section, the developed Gaussian process model was used to conduct a detailed analysis on each of the significant factors. Special attention was paid to the interactions and trends observed. Figure 1 shows these steps in a summary flowchart of the research project. 


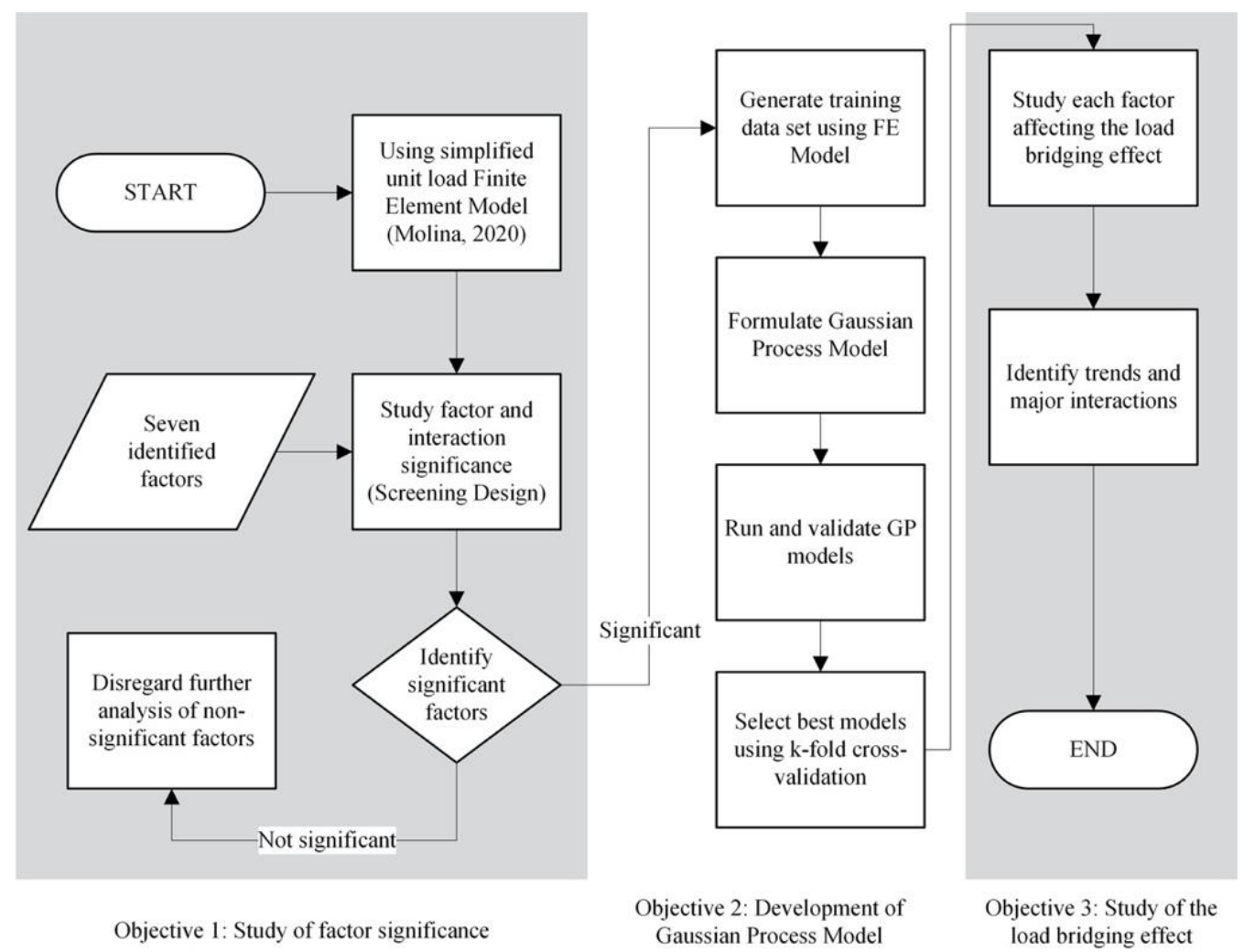

Figure 1. Steps followed to study the effect of load bridging on racked unit loads.

\subsection{Screening of the Significant Factors in the Load Bridging Model}

The finite element model of the unit load segment used in this paper was a twodimensional implicit dynamic model presented by Molina et al. [20]. In it, a segment of a unit load, supported on a warehouse storage racking condition across its width, was simulated. This model simplified the packages to non-deformable boxes with frictional contacts. Boxes were defined by density, and loading was conducted through gravitational acceleration. All components of the model were two-dimensional solid elements using plane/strain linear elastic material. The pallet was modeled through a board analog with 3200 quadrilateral elements sized at $2.54 \mathrm{~mm}$ for the global seed. Boxes were modeled with a mesh generated from elements sized at $12.7 \mathrm{~mm}$ for a total of 6075 elements in the optimal mesh. The solver used was nonlinear, implicit dynamic that allowed for the proper representation of the transient characteristics of the phenomena under study, such as quick box movement, large deflections of the pallet, and nonlinear frictional contacts between each component. This model provided an average prediction accuracy of $8 \%$ for unit load segments with three or more columns of packages. Molina et al. [20] fully describe the finite element model formulation.

After the development of the finite element analysis for the unit load segment, multiple factors were identified as necessary inputs for an accurate simulation. The goal of this research endeavor was to understand and characterize the load bridging effect in unit loads. It was hypothesized that not all input variables would have the same degree of influence on load bridging. Screening for the significant factors and interactions, and then simplifying the load bridging model was a key first step towards comprehending the complex interactions occurring among payloads of stacked corrugated boxes.

Seven variables were identified as necessary to fully describe the unit load segments being replicated in the finite element model; therefore, these variables were selected as the initial factors for the screening design. The variables were as follows: the number of columns, which corresponds to the payload length divided by the box length; the number of layers, which corresponds to the height of the payload divided by the box 
height; the payload height (m); the coefficient of friction between the pallet and the payload (pallet friction); the coefficient of friction between the boxes (box friction); the Young's Modulus of the pallet segment simulator (pallet stiffness, GPa); the total payload weight $(\mathrm{kg})$. All other model inputs were either constants or were derived from the main input variables, such as the material density of the boxes or the specific box dimensions, which depends on the combination of the number of columns, layers, and payload height. Figure 2 shows the unit load segment replicated, graphically depicting each factor.

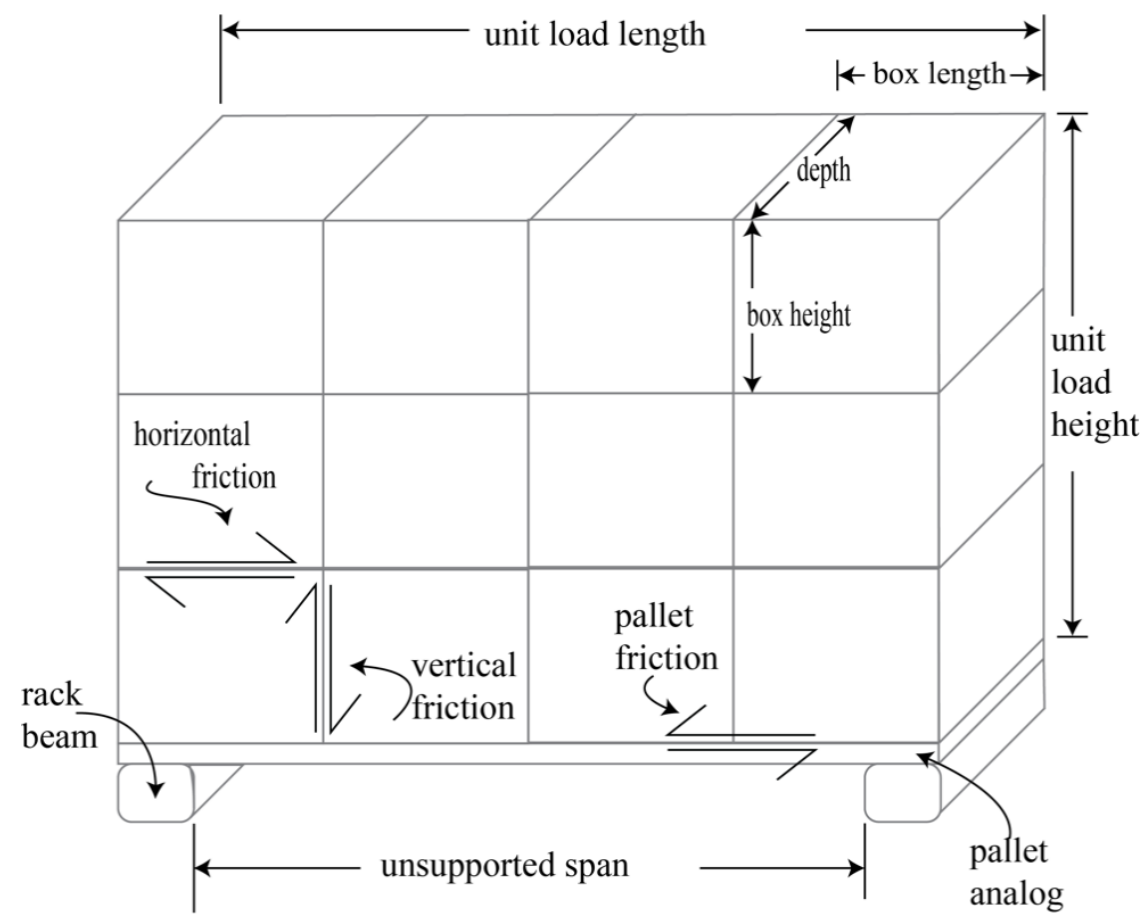

Figure 2. Diagram of the unit load segment and the variables studied [20].

To capture the effects of these variables, values for the study were determined from the trends observed during the model development process in [20]. For the screening design, the unit load segments created consisted of three and five columns, and three and five layers. The coefficient of frictions of the different interactions were selected from a low friction of 0.20 to a high value of 0.60 . This covered the ranges of coefficients of friction (CoFs) observed in material handling operations for different common materials [28]. The Modulus of Elasticity of the pallet was selected for an analog of a flexible, plastic pallet of $2.76 \mathrm{GPa}$ and a more rigid, wooden pallet of $8.27 \mathrm{GPa}$. Pallet stiffness values were estimated based on the expected adjusted bending stiffness rates as developed by Park et al. [16], with a deflection value of $5 \mathrm{~kg} / \mathrm{mm}$ for the low stiffness board and $14 \mathrm{~kg} / \mathrm{mm}$ for the high stiffness board. The payload weight was evaluated for both $109 \mathrm{~kg}$ and $218 \mathrm{~kg}$, which generated an equivalent loading of $538 \mathrm{~kg}$ and $1045 \mathrm{~kg}$, respectively, on a standard pallet size of $1219 \mathrm{~mm} \times 1016 \mathrm{~mm}$. As for the unit load's height, the lowest value selected was $0.762 \mathrm{~m}$ and the highest value was $1.778 \mathrm{~m}$.

Parallel to the study of the factors describing the payload, the finite element model was also modified to calculate the deflection under the same payload weight but as a uniformly distributed load across the pallet deck. These values allowed for the comparison of the relative effects of different factors, controlling for changes of pallet stiffness and payload weight. Deflection ratios have been previously used as a measure of the load bridging levels and can provide a simpler measurement of the rate of change when altering the factors studied. Uniformly distributed loading represents the worse-case scenario for pallet bending and can be experimentally replicated using air or water bags [7]. The ratio is 
calculated by dividing the absolute deflection by the deflection of the pallet analog under uniform loading with the equivalent weight.

\subsection{Design of Experiments for the Screening of the Factors}

To identify the relevant factors in load bridging, a screening design was formulated. The design utilized was a fractional factorial orthogonal $2_{I V}^{7-1}$ design, which allowed for the study of all of the seven main effects and the two-factor interactions between the independent factors included in the model. This generated 64 representations of unit load configurations for the finite element model, with just one partition of the full factorial, thus reducing by half the required experiments from the full factorial design. The resolution $I V$ of the statistical model avoided the main effects being confounded with any of the twofactor interactions. Possible confounding was at its worst with the three-factor interactions. This model simplification is based on the sparsity-of-effects principle. This states that a system, such as the unit load representation at hand, will be dominated by the main effects and low-order interactions and only rarely affected by higher order interactions. No replication was possible, given that the finite element model as formulated provided a deterministic solution. The selection of this statistical model provided enough confidence in a screening design that there was no need for the development of a full factorial, considering the number of runs required. The values for the low and high levels of the seven variables are presented in Table 1 . The main response variable of the model was the absolute pallet segment deflection measured at the center along the $y$-axis. Additionally, the same statistical analysis was conducted for the ratio of the deflection of each experimental test to the deflection of the uniform loading for the pallet segment when loaded with the same load weight. The screening model formulation is presented in (1), where $y$ is the deflection or deflection ratio response, $\beta^{\prime}$ s are the effect coefficients, $x$ represents the coded factors considered in the model, and $n$ equals seven variables.

$$
y=\beta_{0}+\sum_{i=1}^{n} \beta_{i} x_{i}+\sum_{\substack{i, j=1 \\ j \neq i}}^{n} \beta_{i j} x_{i} x_{j}+\sum_{i=1}^{n} \beta_{i i} x_{i}^{2}+\epsilon
$$

Table 1. Factor level combinations for the fractional factorial $2_{\mathrm{IV}}^{7-1}$ design.

\begin{tabular}{cccc}
\hline \multirow{2}{*}{ Variable } & Name & Low (-) & Levels \\
\cline { 3 - 4 } & & $109 \mathrm{~kg}$ & High (+) \\
\hline$x_{1}$ & Payload Weight & 3 & $218 \mathrm{~kg}$ \\
$x_{2}$ & Unit Load Columns & 3 & 5 \\
$x_{3}$ & Unit Load Layers & 0.20 & 5 \\
$x_{4}$ & Pallet Friction & 0.20 & 0.60 \\
$x_{5}$ & Box Friction & $2.76 \mathrm{GPa}$ & 0.60 \\
$x_{6}$ & Pallet Stiffness & $0.762 \mathrm{~m}$ & $8.27 \mathrm{GPa}$ \\
$x_{7}$ & Payload Height & & $1.778 \mathrm{~m}$ \\
\hline
\end{tabular}

Based on the results of the screening design, the main significant effects were subsequently analyzed as a $2^{k}$-full factorial. Removing the factors classified as non-significant after the screening analysis provided enough degrees of freedom from the same data set to conduct a test with a full resolution, given a $k<7$. This is based on the projection properties of the fractional factorials.

\subsection{Development and Cross Validation of a Gaussian Process Model to Predict Unit Load Segment Bending}

From the results of the screening analysis of the unit load bending model, the main significant factors were identified. In order to develop a model that could accurately predict the bending behavior of the boards supporting the payload and the influence of different payload characteristics, each variable was limited to specific ranges, as follows. The number of columns, which relate to the box sizes, was limited to $3,4,5$, and 6 columns 
of stacked boxes along the length of the board. Larger boxes were not part of the validated scope of the model, and smaller boxes, having seven or more columns, were considered too small to be commonly handled on unit loads without any additional shippers. The height of the boxes, in the model referenced as the overall height of the payload, was limited from relatively short unit loads of $508 \mathrm{~mm}$ to tall unit loads of $2.03 \mathrm{~m}$. Very short unit loads, or abnormally tall ones, were not included in the model scope. It is important to note that the number of layers, or the number of divisions that the unit load has along its height, was not considered a significant factor within these ranges. Even though pallet stiffness was not considered a significant factor, this was validated only within the ranges studied, from $2.76 \mathrm{GPa}$ to $8.27 \mathrm{GPa}$. These values are equivalent to a multiple use plastic pallet and a wooden pallet with characteristics similar to a standard pool pallet [15]. Stiffer pallets using different materials, such as metal, might present different behavior, as well as very lightweight plastic pallets; therefore, these were not included in the model. The payload weight range for the unit load segment modeled was the same as for the screening design study, from $109 \mathrm{~kg}$ to $218 \mathrm{~kg}$. When comparing the payload weight for a full unit load on a standard GMA pallet $(1219 \mathrm{~mm} \times 1016 \mathrm{~mm})$, this range correlates to $523 \mathrm{~kg}$ to $1045 \mathrm{~kg}$, using the same pressure level. Although this model's accuracy is expected to be acceptable, even around the limits, moving further away from this range could drastically reduce the prediction's accuracy.

The coefficient of friction $(\mathrm{CoF})$ ranges for the different contact interactions were limited based on the commonly identified ranges for each material. The CoFs of the pallet's top deck's contact with corrugated fiberboard were based on the findings by O'Dell et al. [28], where multiple pallet decks were evaluated for friction characteristics. Plastic pallets with little to no surface treatment presented coefficients around 0.30 , while wooden pallets had values under 0.60 . To account for variability, the model input was limited to between 0.20 and 0.70 . Higher frictions or the use of lips at the edges of the pallets might affect the movement of the components and therefore were not considered. Contacts between corrugated boxes were shown to be between 0.50 and 0.60 [20]. To account for the possibilities of different packaging materials, the model range for the coefficient of friction between the box contacts was between 0.20 and 0.70 . Using material treatments that significantly increase friction, such as tie sheets, could generate different interactions between the components.

In the more traditional approach towards developing response surfaces, the experimenter used the sequential experimentation philosophy, working towards the identification of a small region of interest in order to determine the optimum solution, typically approximated as a low-order polynomial. This study sought to replicate the actual response throughout the whole response region, not only the lowest or highest pallet deflection, since optimization was not the only objective. In order to satisfy this, a space filling design was used in a manner that could cover the complete response region. Additionally, no replication was possible since the finite element model developed was a deterministic model. A space filling design that satisfied the requirements by spreading the design points evenly throughout the region of experimentation was the Latin Hypercube Design (LHD). A Latin Hypercube, with 40 runs and 4 dimensions $(40 \times 4$ matrix), was generated using the computer software JMP Pro 15, which conducts a random permutation to determine the values of each variable for each run. Table 2 presents the factor level combinations for each model run. The same design was used independently for the model of each quantity of columns ( $3,4,5$, or 6 columns). A total of 160 finite element model simulation responses were required.

To fit the deterministic responses from the finite element simulations, a Gaussian process model was used. The Gaussian process model is $y=\mu+z(\mathrm{X})$, where $z(\mathrm{X})$ is Gaussian stochastic process with covariance matrix $\sigma^{2} R(\theta)$. $R(\theta)$ is a correlation matrix with the elements shown in (2). Values for $r_{i j}$ are the correlations between responses at two 
design points. The parameters $\mu$ and $\theta_{s}, \mathrm{~s}=1,2, \ldots, k$ were estimated using the method of maximum likelihood.

$$
r_{i j}=e^{-\sum_{s=1}^{k} \theta_{s}\left(x_{i s}-x_{j s}\right)^{2}}
$$

Table 2. Latin Hypercube Design factor levels for Gaussian process model training data and corresponding finite element model simulation results as a ratio of deflection per unit load model.

\begin{tabular}{|c|c|c|c|c|c|c|c|c|}
\hline \multirow[b]{2}{*}{ ID } & \multirow[b]{2}{*}{$\begin{array}{l}\text { Height } \\
\text { (mm) }\end{array}$} & \multirow[b]{2}{*}{$\begin{array}{c}\text { Pallet } \\
\text { Friction }\end{array}$} & \multirow{2}{*}{$\begin{array}{c}\text { Box } \\
\text { Vertical } \\
\text { Friction }\end{array}$} & \multirow{2}{*}{$\begin{array}{c}\text { Box } \\
\text { Horizontal } \\
\text { Friction }\end{array}$} & \multicolumn{4}{|c|}{ Deflection Ratio by Model } \\
\hline & & & & & $\begin{array}{c}3 \\
\text { Columns }\end{array}$ & $\begin{array}{c}4 \\
\text { Columns }\end{array}$ & $\begin{array}{c}5 \\
\text { Columns }\end{array}$ & $\begin{array}{c}6 \\
\text { Columns }\end{array}$ \\
\hline Run 001 & 508.00 & 0.66 & 0.48 & 0.41 & 0.38 & 0.36 & 0.33 & 0.39 \\
\hline Run 002 & 547.08 & 0.47 & 0.26 & 0.64 & 0.35 & 0.42 & 0.56 & 0.64 \\
\hline Run 003 & 586.15 & 0.61 & 0.24 & 0.34 & 0.35 & 0.37 & 0.53 & 0.64 \\
\hline Run 004 & 625.23 & 0.43 & 0.39 & 0.43 & 0.37 & 0.42 & 0.61 & 0.64 \\
\hline Run 005 & 664.31 & 0.33 & 0.67 & 0.61 & 0.20 & 0.44 & 0.48 & 0.65 \\
\hline Run 006 & 703.38 & 0.46 & 0.52 & 0.23 & 0.48 & 0.41 & 0.46 & 0.65 \\
\hline Run 007 & 742.46 & 0.28 & 0.30 & 0.30 & 0.65 & 0.43 & 0.58 & 0.62 \\
\hline Run 008 & 781.54 & 0.48 & 0.61 & 0.44 & 0.15 & 0.33 & 0.44 & 0.49 \\
\hline Run 009 & 820.62 & 0.25 & 0.34 & 0.55 & 0.36 & 0.42 & 0.56 & 0.65 \\
\hline Run 010 & 859.69 & 0.70 & 0.29 & 0.53 & 0.26 & 0.47 & 0.55 & 0.64 \\
\hline Run 011 & 898.77 & 0.24 & 0.57 & 0.25 & 0.60 & 0.38 & 0.55 & 0.65 \\
\hline Run 012 & 937.85 & 0.65 & 0.64 & 0.29 & 0.10 & 0.20 & 0.30 & 0.34 \\
\hline Run 013 & 976.92 & 0.56 & 0.44 & 0.60 & 0.22 & 0.43 & 0.55 & 0.62 \\
\hline Run 014 & 1016.00 & 0.69 & 0.62 & 0.52 & 0.14 & 0.24 & 0.30 & 0.34 \\
\hline Run 015 & 1055.08 & 0.35 & 0.49 & 0.69 & 0.29 & 0.43 & 0.62 & 0.63 \\
\hline Run 016 & 1094.15 & 0.60 & 0.41 & 0.33 & 0.20 & 0.45 & 0.55 & 0.66 \\
\hline Run 017 & 1133.23 & 0.52 & 0.66 & 0.67 & 0.17 & 0.31 & 0.41 & 0.57 \\
\hline Run 018 & 1172.31 & 0.29 & 0.65 & 0.46 & 0.27 & 0.44 & 0.57 & 0.66 \\
\hline Run 019 & 1211.38 & 0.42 & 0.25 & 0.56 & 0.32 & 0.43 & 0.58 & 0.64 \\
\hline Run 020 & 1250.46 & 0.20 & 0.43 & 0.39 & 0.34 & 0.46 & 0.59 & 0.64 \\
\hline Run 021 & 1289.54 & 0.38 & 0.42 & 0.24 & 0.29 & 0.42 & 0.63 & 0.63 \\
\hline Run 022 & 1328.62 & 0.41 & 0.47 & 0.48 & 0.28 & 0.43 & 0.57 & 0.64 \\
\hline Run 023 & 1367.69 & 0.30 & 0.23 & 0.37 & 0.32 & 0.45 & 0.59 & 0.64 \\
\hline Run 024 & 1406.77 & 0.53 & 0.20 & 0.32 & 0.34 & 0.45 & 0.60 & 0.64 \\
\hline Run 025 & 1445.85 & 0.49 & 0.70 & 0.38 & 0.14 & 0.32 & 0.42 & 0.66 \\
\hline Run 026 & 1484.92 & 0.64 & 0.32 & 0.49 & 0.27 & 0.43 & 0.59 & 0.65 \\
\hline Run 027 & 1524.00 & 0.23 & 0.33 & 0.58 & 0.32 & 0.44 & 0.58 & 0.64 \\
\hline Run 028 & 1563.08 & 0.67 & 0.51 & 0.20 & 0.18 & 0.32 & 0.40 & 0.43 \\
\hline Run 029 & 1602.15 & 0.34 & 0.69 & 0.62 & 0.24 & 0.47 & 0.55 & 0.64 \\
\hline Run 030 & 1641.23 & 0.62 & 0.53 & 0.47 & 0.17 & 0.32 & 0.42 & 0.43 \\
\hline Run 031 & 1680.31 & 0.58 & 0.35 & 0.70 & 0.27 & 0.45 & 0.62 & 0.64 \\
\hline Run 032 & 1719.38 & 0.21 & 0.55 & 0.51 & 0.39 & 0.46 & 0.58 & 0.65 \\
\hline Run 033 & 1758.46 & 0.26 & 0.56 & 0.28 & 0.33 & 0.45 & 0.58 & 0.63 \\
\hline Run 034 & 1797.54 & 0.39 & 0.46 & 0.65 & 0.29 & 0.45 & 0.63 & 0.64 \\
\hline Run 035 & 1836.62 & 0.37 & 0.28 & 0.21 & 0.31 & 0.44 & 0.58 & 0.64 \\
\hline Run 036 & 1875.69 & 0.55 & 0.38 & 0.35 & 0.26 & 0.45 & 0.62 & 0.64 \\
\hline Run 037 & 1914.77 & 0.44 & 0.21 & 0.57 & 0.34 & 0.45 & 0.59 & 0.65 \\
\hline Run 038 & 1953.85 & 0.32 & 0.37 & 0.42 & 0.36 & 0.45 & 0.59 & 0.65 \\
\hline Run 039 & 1992.92 & 0.57 & 0.60 & 0.66 & 0.19 & 0.32 & 0.40 & 0.46 \\
\hline Run 040 & 2032.00 & 0.51 & 0.58 & 0.26 & 0.19 & 0.39 & 0.54 & 0.51 \\
\hline
\end{tabular}

Predicted values for the responses of the Gaussian process model are generated from (3). $\hat{\mu}$ and $\hat{\theta}$ are the maximum likelihood estimates of the model parameters $\mu$ and $\theta$, respectively, and $r^{\prime}(x)=\left[r\left(x_{1}, x\right), r\left(x_{2}, x\right), \ldots, r\left(x_{n}, x\right)\right]$. This prediction equation contains one term for each of the design points in the original experiment.

$$
\hat{y}(x)=\hat{\mu}+r^{\prime}(x) R(\hat{\theta})^{-1}(y-j \hat{\mu})
$$


In order to generate the most accurate model and to validate the prediction results from the Gaussian Process model, a $k$-fold cross validation was conducted. The response data set for each per column model was divided into five equal parts. The GP model was run five separate times with only four-fifths of the data. The remaining data points were used to conduct the cross validations. The model with the data set that provided the highest accuracy was selected as the resulting statistical model. Goodness of fit and predictive performance was evaluated by comparing the Root Mean Square Error (RMSE) of the predictions against the finite element model simulation results, as well as the Mean Absolute Percent Error (MAPE). Both error measurements together provided enough confidence to determine model accuracy.

\subsection{Study of the Significant Factors Influencing Load Bridging}

With the goal of better understanding the behavior of each of the significant factors influencing load bridging, a detailed analysis was conducted. The GP model was applied to study the behavior of each factor, in an almost one-factor at a time (OFAT) style of analysis, but this study also took into consideration major interactions. The results inform and support the decision-making process of unit load design. Given the many interactions acting upon the bending response of the board, the full model should be applied to specific unit load evaluations. The analysis was limited to the dimensions studied in the Latin Hypercube Design since that was the range of the input data of the model. A summary of the factor ranges is shown in Table 3. All other variables not included here were also limited to this project's scope.

Table 3. Factor limiting ranges for each significant variable in the Gaussian Process Model.

\begin{tabular}{ccc}
\hline \multirow{2}{*}{ Factor } & \multicolumn{2}{c}{ Factor Range } \\
\cline { 2 - 3 } & Minimum & Maximum \\
\hline Unit Load Columns & 3 & 6 \\
Pallet Friction & 0.20 & 0.70 \\
Box Friction & 0.20 & 0.70 \\
Payload Height (mm) & 508 & 2030 \\
\hline
\end{tabular}

\section{Results}

\subsection{Results for the Screening of the Factors}

The finite element simulation for uniform loading was conducted for both low and high stiffness pallet segments. Table 4 shows the deflection results for the simulations of low and high stiffness boards when loaded with uniformly distributed forces of $109 \mathrm{~kg}$ and $218 \mathrm{~kg}$, respectively, equivalent to $4.14 \mathrm{kPa}$ and $8.27 \mathrm{kPa}$ across the pallet segment's top deck.

Table 4. Simulation results for low and high stiffness pallet segments deflection $(\mathrm{mm})$ under uniformly distributed loading.

\begin{tabular}{cccc}
\hline & & \multicolumn{2}{c}{$\begin{array}{c}\text { Deflection } \\
(\mathbf{m m})\end{array}$} \\
\cline { 3 - 4 } $\begin{array}{c}\text { Pallet } \\
\text { Segment }\end{array}$ & $\begin{array}{c}\text { Stiffness } \\
\text { (GPa) }\end{array}$ & $\mathbf{1 0 8} \mathbf{~ k g}$ & $\mathbf{2 1 8} \mathbf{~ k g}$ \\
\hline Low stiffness & 2.76 & 22.7 & 44.9 \\
High stiffness & 8.27 & 7.51 & 14.7 \\
\hline
\end{tabular}

The complete unit load finite element (FE) model was solved for the 64 factor level combinations. Table 5 shows the individual $p$-values for each of the main factors and all of the second order interactions when using absolute pallet deflection as the main response. Effects and interactions were considered significant when they had a $p$-value lower than the selected $p$-value of 0.10 or when a higher order interaction included such effects. The 
$p$-value limit of 0.10 was selected to decrease the probability of rejecting variables with lower levels of influence. These are considered to be the factors influencing the load bridging effect, which require further exploration.

Table 5. Fractional factorial $p$-values for the factors and 2nd-interactions of the initial screening design by board deflection $(\mathrm{mm})$ and deflection ratio as main response. Factors below divider were considered non-significant ( $p$-value $>0.10)$.

\begin{tabular}{|c|c|c|c|}
\hline \multicolumn{2}{|c|}{ Response: Deflection (mm) } & \multicolumn{2}{|c|}{ Response: Deflection Ratio } \\
\hline Term & $p$-Value & Term & $p$-Value \\
\hline Pallet Stiffness & $<0.0001$ & Pallet Friction & $<0.0001$ \\
\hline Pallet Friction & $<0.0001$ & Columns & $<0.0001$ \\
\hline Weight & 0.0001 & Height $\times$ Pallet Friction & $<0.0001$ \\
\hline Pallet Stiffness $\times$ Weight & 0.0001 & Height & $<0.0001^{\wedge}$ \\
\hline Box Friction & 0.0002 & Columns $\times$ Height & 0.0001 \\
\hline Height & 0.0002 & Box Friction & 0.0001 \\
\hline Box Friction $\times$ Pallet Stiffness & 0.0009 & Height $\times$ Box Friction & 0.0006 \\
\hline Columns & 0.0010 & Columns $\times$ Pallet Friction & 0.0309 \\
\hline Pallet Friction $\times$ Pallet Stiffness & 0.0015 & Pallet Friction $\times$ Box Friction & 0.0693 \\
\hline Columns $\times$ Height & 0.0017 & Box Friction $\times$ Pallet Stiffness & 0.1511 \\
\hline Height $\times$ Pallet Friction & 0.0023 & Layers $\times$ Box Friction & 0.2088 \\
\hline Columns $\times$ Pallet Stiffness & 0.0104 & Columns $\times$ Box Friction & 0.2088 \\
\hline Height $\times$ Box Friction & 0.0134 & Weight & 0.2789 \\
\hline Pallet Friction $\times$ Weight & 0.0328 & Columns $\times$ Layers & 0.3396 \\
\hline Pallet Friction $\times$ Box Friction & 0.0397 & Layers & $0.3489^{\wedge}$ \\
\hline Height $\times$ Pallet Stiffness & 0.0432 & Height $\times$ Weight & 0.4402 \\
\hline Columns $\times$ Weight & 0.0695 & Layers $\times$ Pallet Friction & 0.4586 \\
\hline Box Friction $\times$ Weight & 0.1127 & Height $\times$ Pallet Stiffness & 0.4966 \\
\hline Layers $\times$ Pallet Friction & 0.1460 & Pallet Stiffness $\times$ Weight & 0.6204 \\
\hline Columns $\times$ Box Friction & 0.2057 & Layers $\times$ Pallet Stiffness & 0.6424 \\
\hline Columns $\times$ Pallet Friction & 0.2075 & Layers $\times$ Height & 0.7101 \\
\hline Height $\times$ Weight & 0.5336 & Pallet Friction $\times$ Weight & 0.8768 \\
\hline Layers $\times$ Pallet Stiffness & 0.6632 & Layers $\times$ Weight & 0.9013 \\
\hline Layers $\times$ Height & 0.7221 & Box Friction $\times$ Weight & 0.9013 \\
\hline Layers $\times$ Weight & 0.8300 & Pallet Stiffness & $0.9714^{\wedge}$ \\
\hline Layers $\times$ Box Friction & 0.8668 & Columns $\times$ Pallet Stiffness & 0.9753 \\
\hline Columns $\times$ Layers & 0.9477 & Columns $\times$ Weight & 1.0000 \\
\hline Layers & $0.9577^{\wedge}$ & Pallet Friction $\times$ Pallet Stiffness & 1.0000 \\
\hline
\end{tabular}

As expected, the stiffness of the board and the load applied are very significant factors influencing the resulting bending moment. Alternatively, when looking at the effect from the perspective of the change in deflection, which is the deflection ratio, weight and stiffness are non-significant factors. From a fundamental perspective, this is understandable since the ratio of deflection accounts for changes in stiffness and weight. It is important to note that these variables are not influencing the effects of other variables. No significant interaction for the deflection ratio analysis includes either payload weight or board stiffness. With this, it can be assumed that the rate of effect for the other factors, such as number of columns or payload height, are independent of the overall payload weight and pallet stiffness. Previous experimental studies have observed that, while maintaining the payload weight as a constant, load bridging is not relevant for high stiffness pallets. This suggests an interaction between pallet stiffness and load bridging $[7,12-14,16]$. Very high stiffness pallets present very low deflection results. Therefore, in order to be able to identify minute changes, extremely high consistency between experimental units and precise measurements are required. Such precision levels cannot always be achieved with current unit load testing methods. Molina et al. [13] briefly explored the load bridging effects of modifying pallet stiffnesses but not the weight of the payload. It was noted that higher stiffness pallets 
carrying a lighter load do not experience significant load bridging. There is a complete absence of a measurable bending response of the pallet.

Besides pallet stiffness and payload weight, it is worth noting that the number of layers in the unit load does not seem to influence the pallet segment's bending results, either as a main effect or as part of an interaction of higher order for either of the two analyses. The other four effects that were analyzed were considered significant regardless of the response variable studied. Multiple interactions were also identified as significant, supporting this study's hypothesis that interactions between multiple factors are significant and have not been properly studied before.

A $2^{4}$ full factorial design analysis was conducted using the model results from the screening design. This took advantage of the projection properties of the fractional designs. Deflection ratios were considered the main model response. The main factors were number of columns, payload height, pallet friction, and box friction. According to the screening design results, pallet stiffness, payload weight, and number of layers do not significantly affect the pallet bending ratio and therefore were excluded. Table 6 shows the effect summary $p$-values of the analysis. It was confirmed that there are four main effects significant in load bridging. Certain second order interactions were also found to be significant to the load bridging effect, as well as multiple third order interactions. This preliminary exploration shows the complexity of the load bridging effect, where every factor must be studied in coordination with the changes to other factors. It is not feasible to conduct such experimentation with traditional physical experimental methods.

Table 6. Results of the $2^{4}$-full factorial design ANOVA ( $p$-values) for the significant effects of on the board deflection ratio.

\begin{tabular}{cc}
\hline Source & $p$-Value \\
\hline Pallet Friction & $<0.0001$ \\
Columns & $<0.0001$ \\
Height & $<0.0001$ \\
Box Friction & $<0.0001$ \\
Height $\times$ Pallet Friction & $<0.0001$ \\
Height $\times$ Box Friction & $<0.0001$ \\
Columns $\times$ Height $\times$ Pallet Friction & $<0.0001$ \\
Columns $\times$ Height $\times$ Box Friction & 0.0002 \\
Columns $\times$ Pallet Friction & 0.0013 \\
Height $\times$ Pallet Friction $\times$ Box Friction & $0.0025^{\wedge}$ \\
Columns $\times$ Box Friction & 0.0032 \\
Columns $\times$ Pallet Friction $\times$ Box Friction & $0.0749^{\wedge}$ \\
Pallet Friction $\times$ Box Friction & 0.2725 \\
Columns $\times$ Height $\times$ Pallet Friction $\times$ Box Friction & $0.2773^{\wedge}$ \\
\hline M. & 0.5086 \\
\hline
\end{tabular}

" denotes effects with containing effects above them.

\subsection{Gaussian Process Model Results}

Simulations were conducted using the unit load segment finite element model for each of the 160 data points determined by the Latin Hypercube design. Results are presented in Table 2. This was the data input needed to compute the Gaussian process regression. Root Means Square Error (RMSE) and Mean Absolute Percent Error (MAPE) results are presented in Table 7. For each of the unit load representations, the model with the lowest MAPE and RMSE was selected. The data subset of $\mathrm{k}=4$ was selected as the one with the best goodness of fit for all four models. The overall error level of the GP model was considered low, with an average RMSE of 0.05 and a MAPE of 0.08 . The highest error level was for the model with three columns, and it had an RMSE of 0.05 and a MAPE of 0.13 . The highest prediction accuracy was presented in the six-column model, with a RMSE of 0.03 and a MAPE of 0.03 . 
Table 7. Root Means Square Error (RMSE) and Mean Absolute Percent Error (MAPE) for the Gaussian process prediction for each cross validated data set.

\begin{tabular}{ccccccc}
\hline \multirow{2}{*}{$\begin{array}{c}\text { Cross } \\
\text { Validation } \\
\text { Index (k) }\end{array}$} & $\begin{array}{c}\text { Error } \\
\text { Measurement }\end{array}$ & $\begin{array}{c}\mathbf{3} \\
\text { Columns }\end{array}$ & $\begin{array}{c}\mathbf{4} \\
\text { Columns }\end{array}$ & $\begin{array}{c}\mathbf{5} \\
\text { Columns }\end{array}$ & $\begin{array}{c}\mathbf{6} \\
\text { Columns }\end{array}$ & $\begin{array}{c}\text { Model } \\
\text { Average }\end{array}$ \\
\hline 1 & & 0.26 & 0.06 & 0.10 & 0.05 & 0.12 \\
2 & MAPE & 0.22 & 0.17 & 0.07 & 0.04 & 0.12 \\
3 & & 0.24 & 0.06 & 0.07 & 0.07 & 0.11 \\
4 & & 0.13 & 0.06 & 0.09 & 0.03 & 0.08 \\
5 & 0.12 & 0.09 & 0.08 & 0.17 & 0.11 \\
\hline 1 & & 0.06 & 0.04 & 0.05 & 0.05 & 0.05 \\
2 & & 0.05 & 0.07 & 0.04 & 0.02 & 0.05 \\
3 & RMSE & 0.08 & 0.03 & 0.04 & 0.06 & 0.06 \\
4 & & 0.05 & 0.04 & 0.06 & 0.03 & 0.05 \\
5 & & 0.10 & 0.05 & 0.06 & 0.09 & 0.08 \\
\hline
\end{tabular}

The Gaussian process model provides a reliable method to efficiently predict the ratio of change in the bending of a unit load segment, with a low error estimate. This is a significant aspect since finite element modeling places a high initial cost to conduct everyday analysis of unit load design.

\subsection{Results of the Internal Stresses' Distribution and Trends}

The changes in stress distributions when varying different payloads can provide additional insights into how pallet performance can be affected besides the bending response studied.

As previously mentioned, pallets are commonly evaluated by applying a uniformly distributed load on the pallet's top deck. A similar analysis on the pallet analog developed provides a maximum Von Mises equivalent stress of $6.78 \mathrm{MPa}$ on the center span of the structure, when loaded with a uniform pressure of $4.14 \mathrm{kPa}$. The aforementioned pressure is equivalent to $109 \mathrm{~kg}$ of total load for the unit load segment, and the resulting plot is shown in Figure 3. The pallet analog was modelled after PMMA which has a yield strength of $72 \mathrm{MPa}$ [29]. The current internal stresses under uniform loading represent $9.37 \%$ of yield.
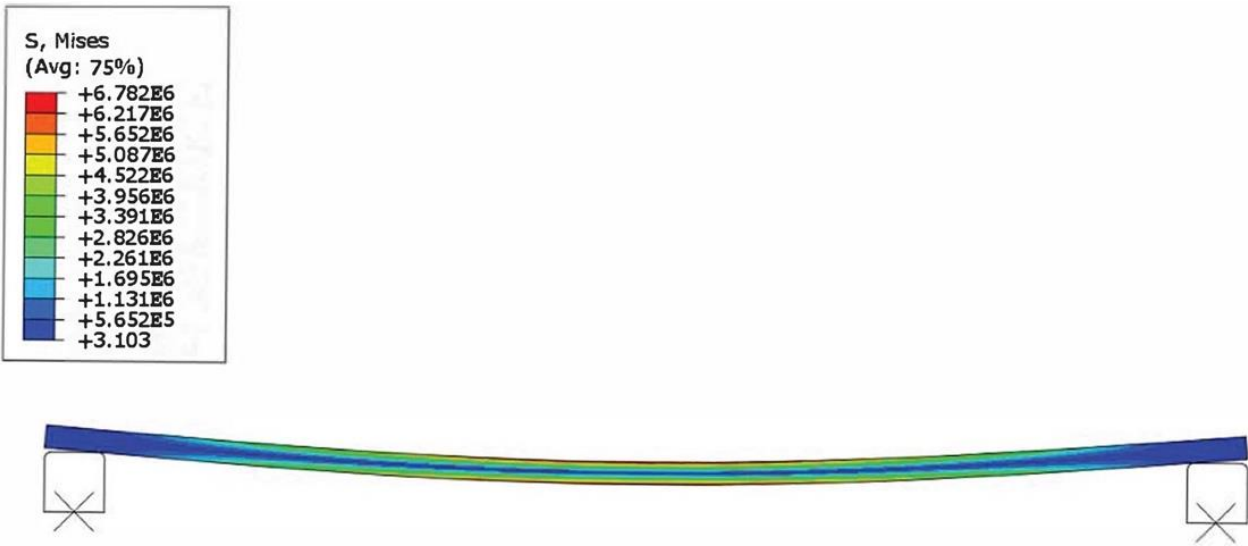

Figure 3. Plot of the equivalent Von Mises stress (Pa) of the pallet analog under uniformly distributed loading of $4.14 \mathrm{kPa}$.

As shown in Figure 4, the Von Mises equivalent stress presents a distribution that closely follows a parabola, with a symmetric distribution along the pallet analog and with the vertex matching the center of the unsupported span. 


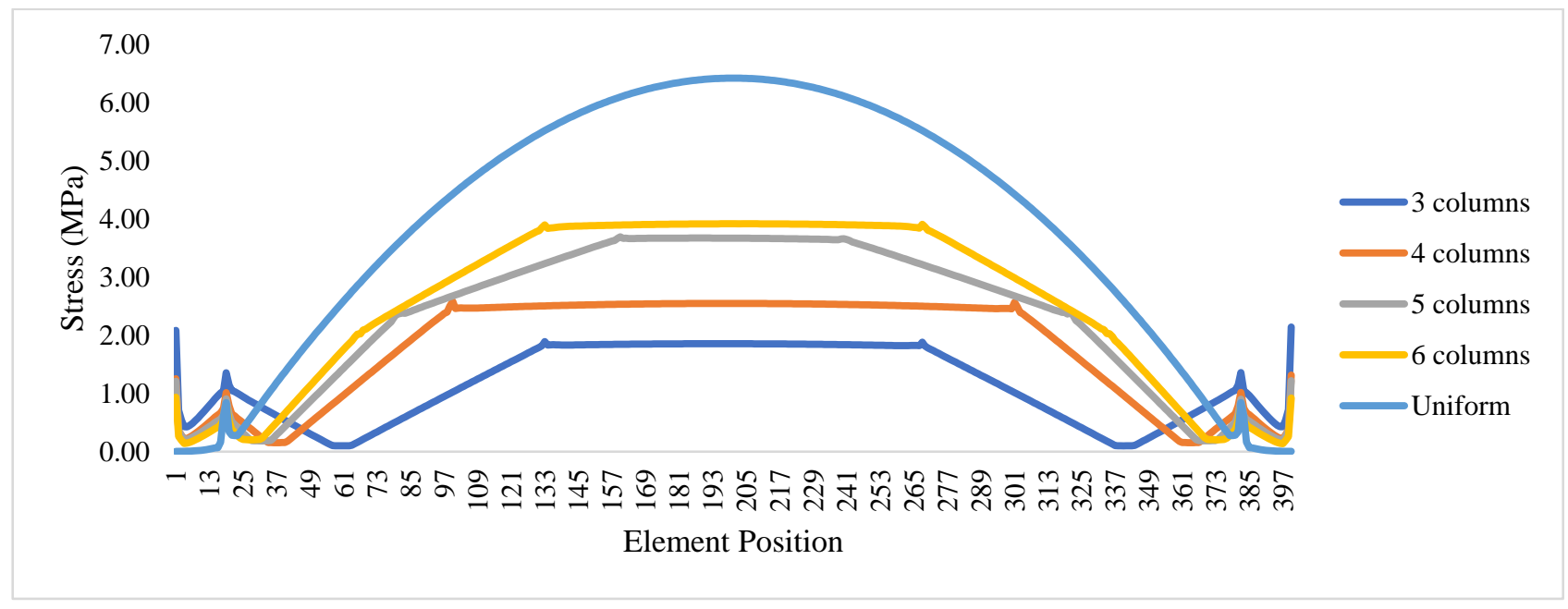

Figure 4. Plot of the maximum equivalent Von Mises stresses (MPa) for the unit load segments under five different payloads.

When discrete loading is applied through the use of stacked corrugated boxes, the stress distribution changes. As shown in Figure 4, the distribution of stresses along the pallet analog changes as the payload characteristics are changed. In this example, each of the payloads have the same characteristics except for the dimensions of the boxes. Unit load height and all coefficients of friction remained constant. Table 8 shows the percent change for the deflection response and for the equivalent Von Mises stresses. Although the change is not completely equivalent, both variables presented a similar trend of change when decreasing the size of the boxes. Figures 5-8 show the equivalent Von Mises stress plots for each of the unit load segments studied. Using the Von Mises stresses for the high-strain, ductile material modelled (PMMA), allows for a reasonable estimation of the yield strength of the pallet analog. The reduction in the peak stresses experienced when comparing the specific payloads versus uniform loading indicate that the pallet analog yield strength can increase from $63.7 \%$ ( 6 columns) to $245 \%$ ( 3 columns). This increase is generated exclusively through the load bridging effect.

Table 8. Changes in deflection and maximum equivalent stresses from uniformly distributed loading to discrete number of boxes.

\begin{tabular}{ccccc}
\hline & Deflection $(\mathbf{m m})$ & Change & $\begin{array}{c}\text { V. Mises Stress } \\
\text { (MPa) }\end{array}$ & Change \\
\hline Uniform & 22.70 & - & 6.42 & - \\
3 columns & 7.72 & $-66 \%$ & 1.85 & $-67 \%$ \\
4 columns & 10.44 & $-54 \%$ & 2.55 & $-57 \%$ \\
5 columns & 13.39 & $-41 \%$ & 3.67 & $-41 \%$ \\
6 columns & 14.53 & $-36 \%$ & 3.92 & $-37 \%$ \\
\hline
\end{tabular}

In analyzing the stress concentrations along the pallet analog, every payload presented high stresses at the ends of the boards, where boxes were contacting the corners of the pallet analog and at the locations of the rigid supports. Since these pressure concentrations were considered a result of the modeling simplification, they can be ignored for the purposes of the load bridging analysis. Excluding these sections, most of the stress distributions followed a clear trend, where the stresses present a change in each of the locations where the boxes' edges contacted the pallet deck.

The knowledge provided by these trends in the changes to the internal stresses, and how they closely relate to the bending response, can inform unit load designers about potential changes in pallet strength performance that must be validated further. 

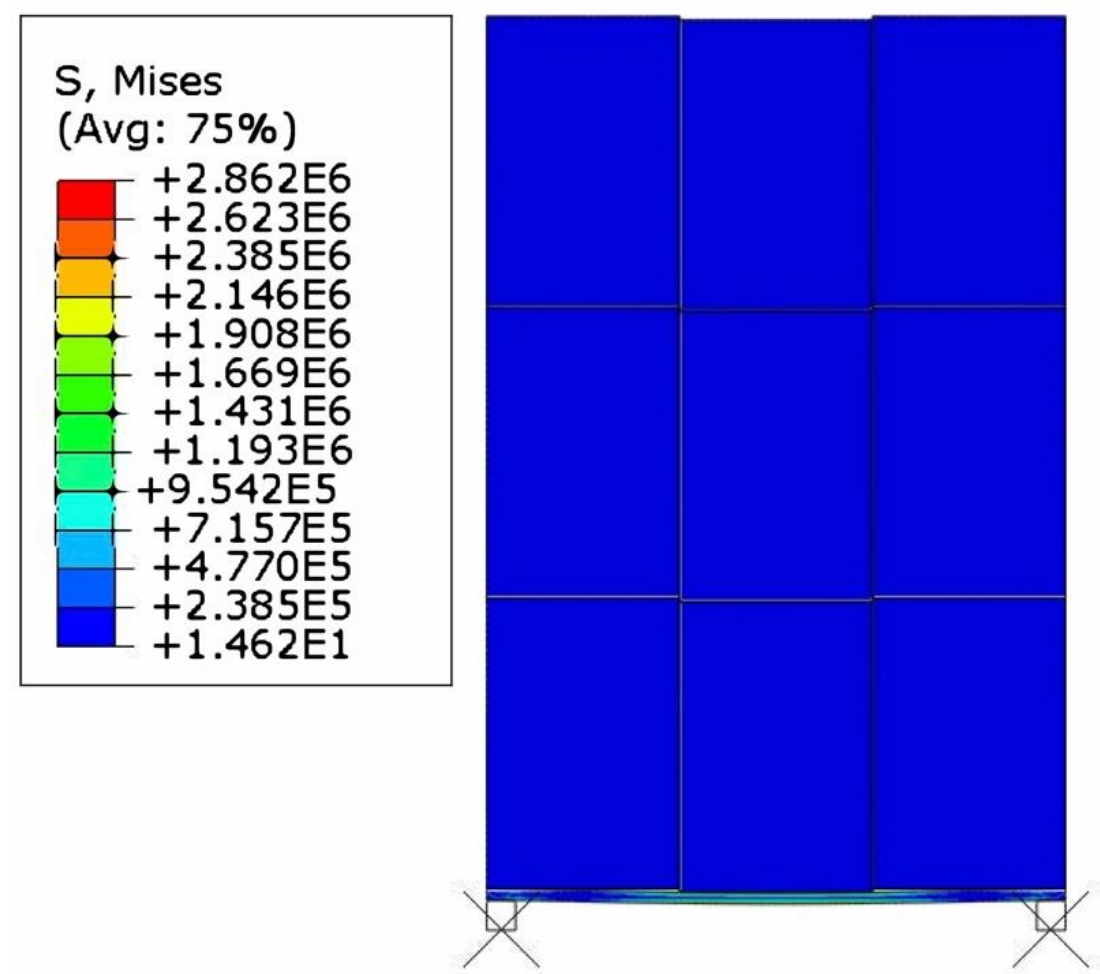

Figure 5. Plot of the equivalent Von Mises (MPa) stress of the unit load segment under a 3-column payload.
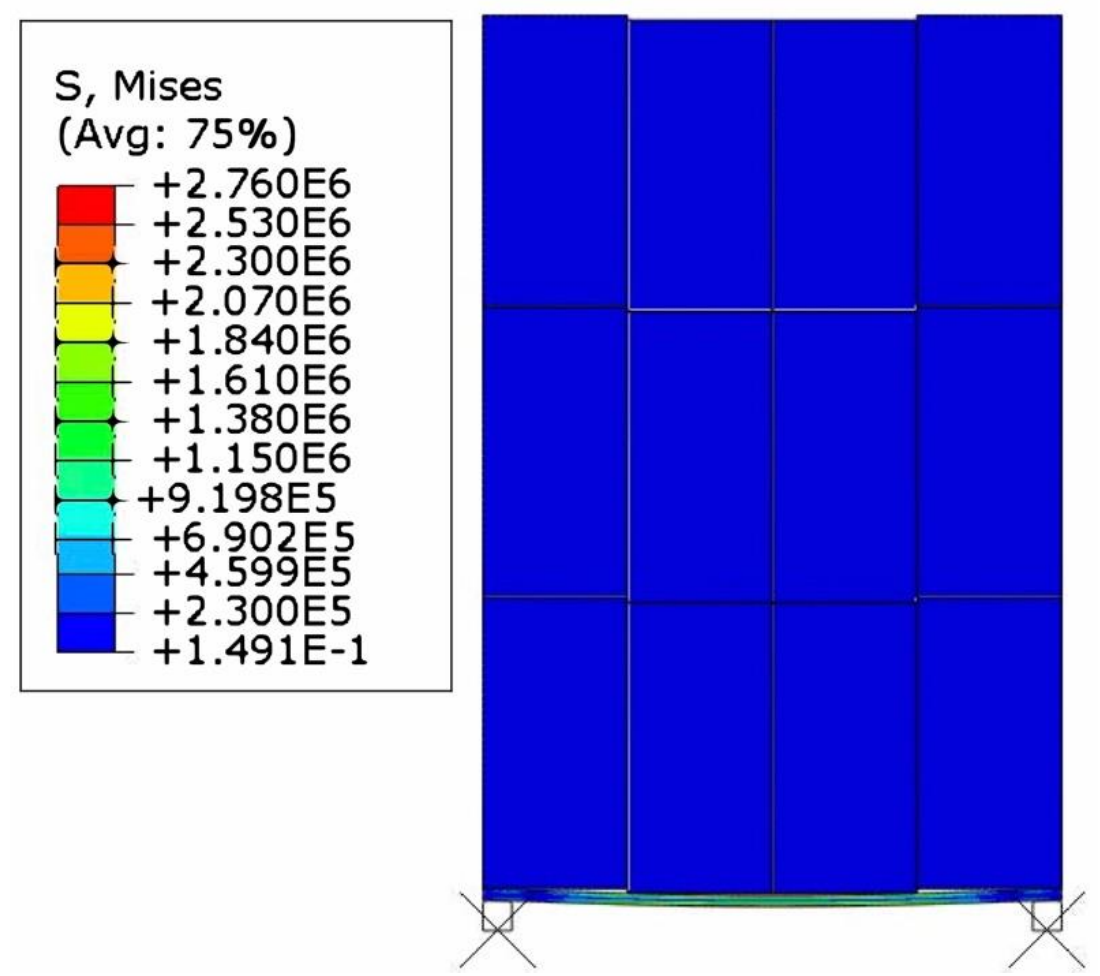

Figure 6. Plot of the equivalent Von Mises (MPa) stress of the unit load segment under a 4-column payload. 

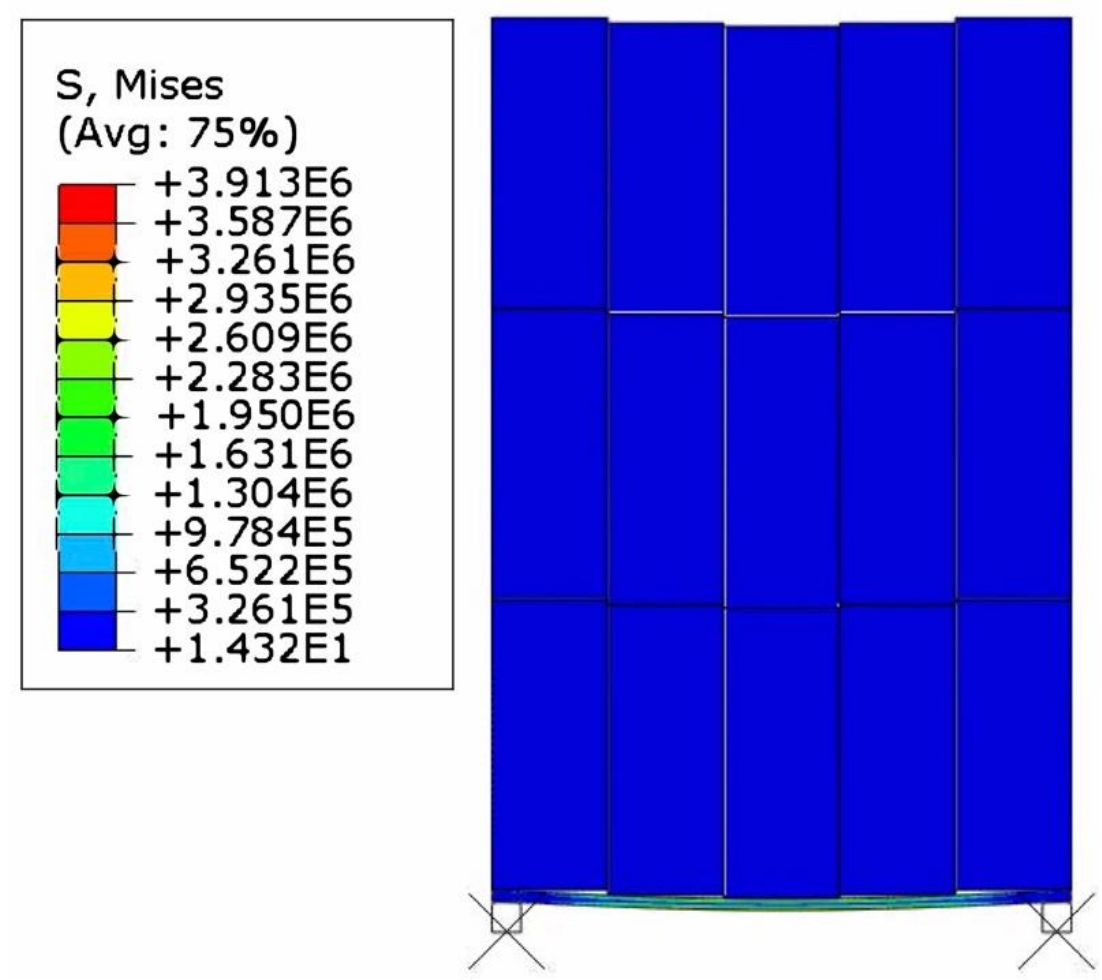

Figure 7. Plot of the equivalent Von Mises (MPa) stress of the unit load segment under a 5-column payload.
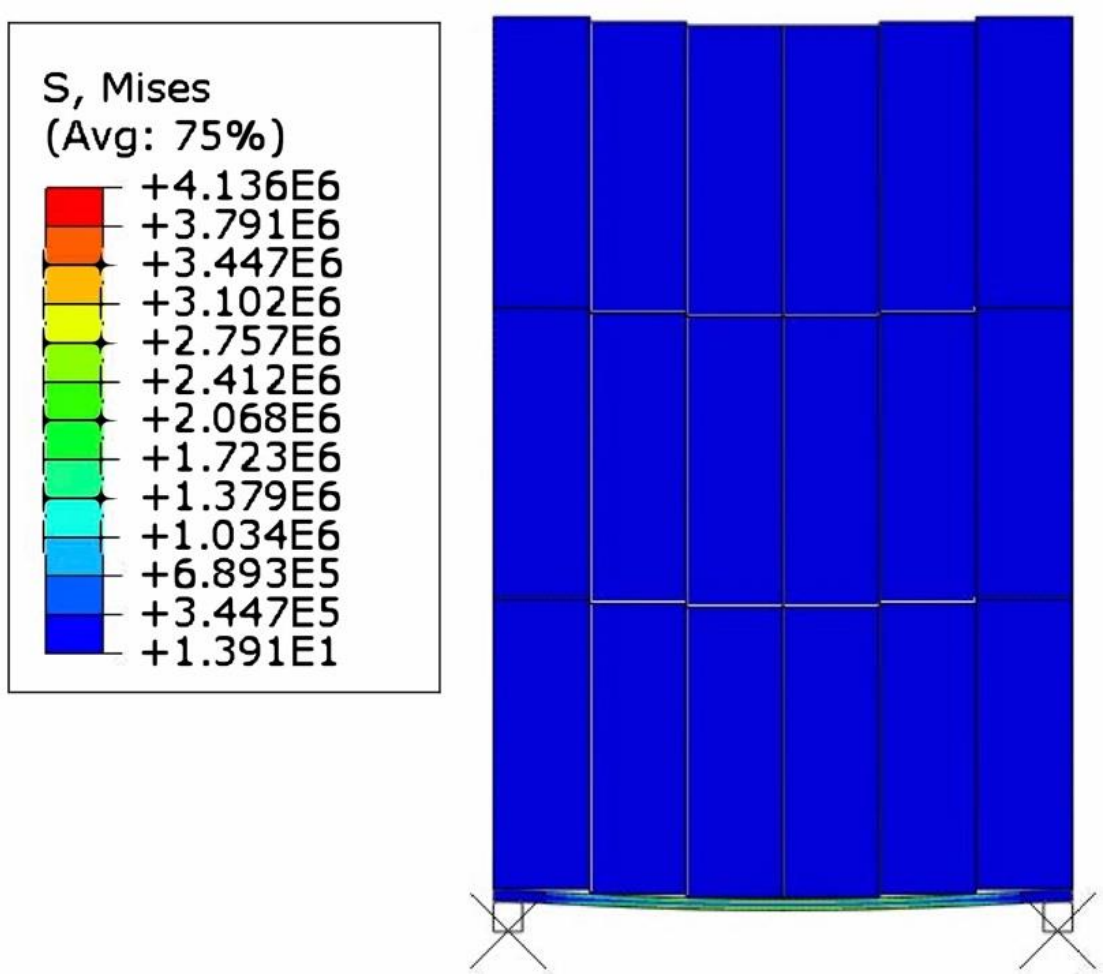

Figure 8. Plot of the equivalent Von Mises (MPa) stress of the unit load segment under a 6-column payload. 


\section{Discussion}

\subsection{Discussion on the Load Bridging Effects and Trends by Each Significant Factor}

\subsubsection{Effect of Number of Columns on the Bending of a Board}

Although the Gaussian process models were formulated independently for unit loads with different numbers of columns, the results can be grouped together to identify relevant trends in the data. Previous researchers have identified that the size of the boxes has a very significant influence on load bridging levels generated [12,16]. In general, it is commonly assumed that smaller boxes generate higher bending. This hypothesis is based on the application of the discrete load on the pallet deck. Infinitely smaller boxes will resemble a uniformly distributed load and, therefore, generate the same bending as uniform load applicators. Figure 9 shows that same overall trend for most scenarios studied. It is of high relevance to note that when boxes are longer along the length (three columns), the payload is relatively short $(700 \mathrm{~mm})$ and the box-to-pallet CoF is low (0.30), this observed trend is no longer valid. In this scenario, the unit load with three columns of boxes presented a deflection ratio of 0.65 , while that for four columns was 0.43 , five columns was 0.59 , and six columns was 0.64 . Unit loads with these characteristics present a higher deflection than those with smaller boxes, almost matching the same deflection level as a unit load with six columns. The interaction of the box length dimension with low friction properties generated higher deflection than one driven mostly by box size. As observable in Figure 10, the rotational movement of the boxes when the board was under load was different for the unit load of three columns (Figure 10a) than for those with a higher number of columns. The same change in the movement of the boxes was generated by maintaining the number of columns but either increasing the friction coefficient of the pallet (Figure 10b) or the overall height of the payload (Figure 10c). This confirmed that no generalization can be made regarding the effect of box size on load bridging without considering the remaining interacting factors as well. A key aspect in reducing board deflection was to prevent the rotating movement of the packages. This was possible through many different combinations of factors. Because of this, no specific attempts to quantify a threshold point were made, avoiding misinterpretation of the model results.

The effect of the pallet friction levels can be observed for a commonly used unit load scenario. The unit load is supported on a $1219 \mathrm{~mm} \times 1016 \mathrm{~mm}$ wooden pallet $(0.45$ pallet top deck friction) and contains corrugated boxes made of kraft paper (average box friction of 0.45 ) that are stacked to a total height of $1200 \mathrm{~mm}$. Everything else remaining equal, increasing the box length of such a unit load from $169 \mathrm{~mm}$ to $338 \mathrm{~mm}$ reduces the experienced initial deflection by $60 \%$, from a ratio of 0.64 to 0.25 . Taking into account the relationship between box size and pallet performance can influence the design process of tertiary packaging.

\subsubsection{Effect of the Payload Height on the Bending Ratio of a Board}

The height of the payload was identified as a significant factor influencing the bending of the pallet deck. When analyzing the height on a range between $500 \mathrm{~mm}$ and $2 \mathrm{~m}$, and for a range of friction coefficients and number of columns, it can be observed that the effect of height is highly dependent on the other variables, as shown in Figure 11. Park [15] conducted preliminary experimentations on the effect of payload height. Using large, corrugated boxes (arranged in two columns), Park identified the fact that by increasing the height of the unit load, there was a significant decrease in the overall board bending response. A similar trend can be observed in the model's response for unit loads consisting of three columns. However, as the boxes became smaller, the effect of height was no longer relevant. The movement of the boxes, such as in Figure 10, for six columns, was mostly downwards. There was no rotational movement on unit loads with low payload heights having the same total weight per column, so the load perceived by the board was not changed, therefore it generated the same board deflection ratios. For the majority of boxes used in the field, changing the height of the boxes or adding additional layers of the same package will not significantly change the resulting deflection. 


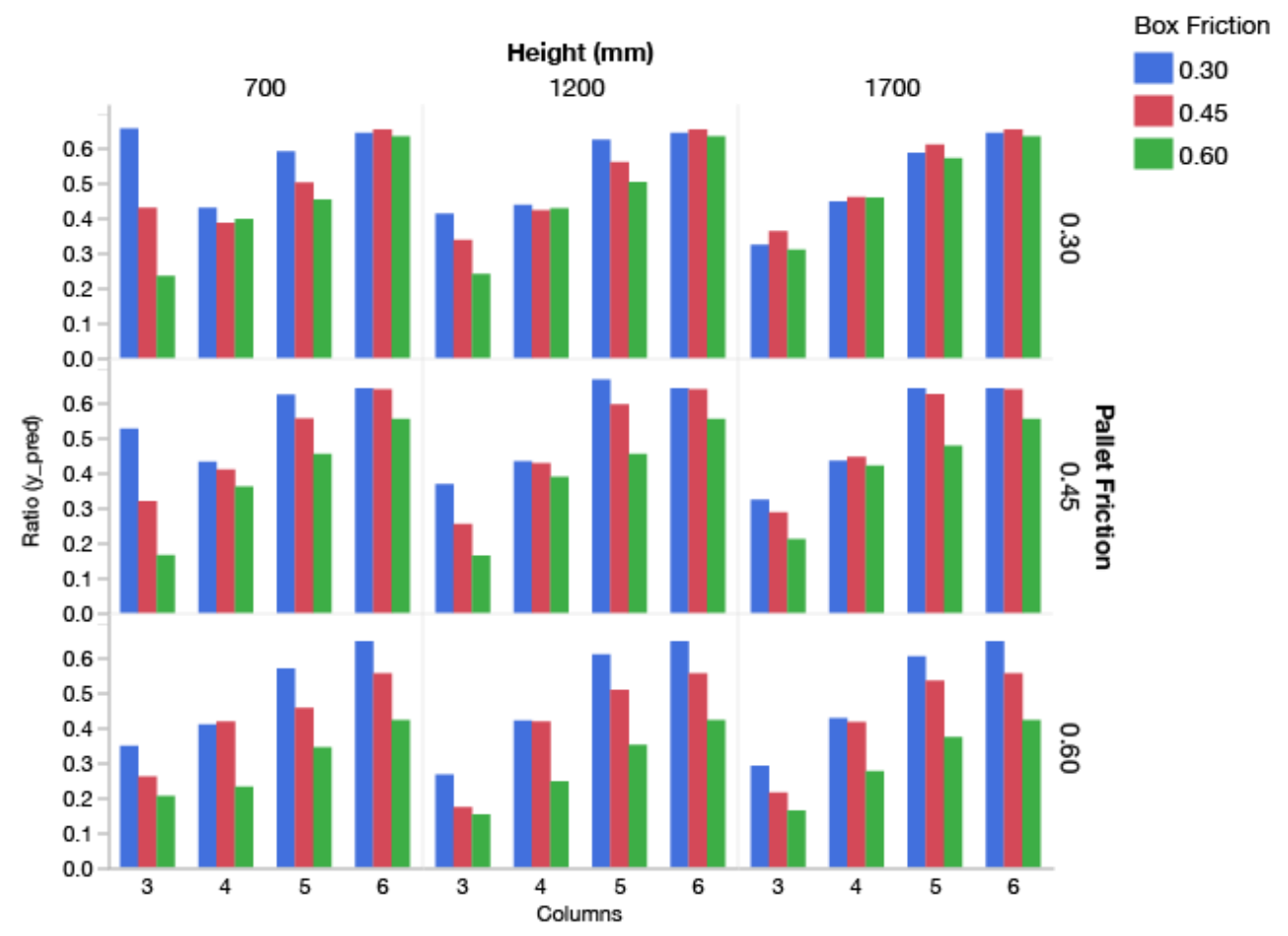

Figure 9. Effect of number of columns on board bending ratio by height $(\mathrm{mm})$, box friction and pallet friction coefficients.

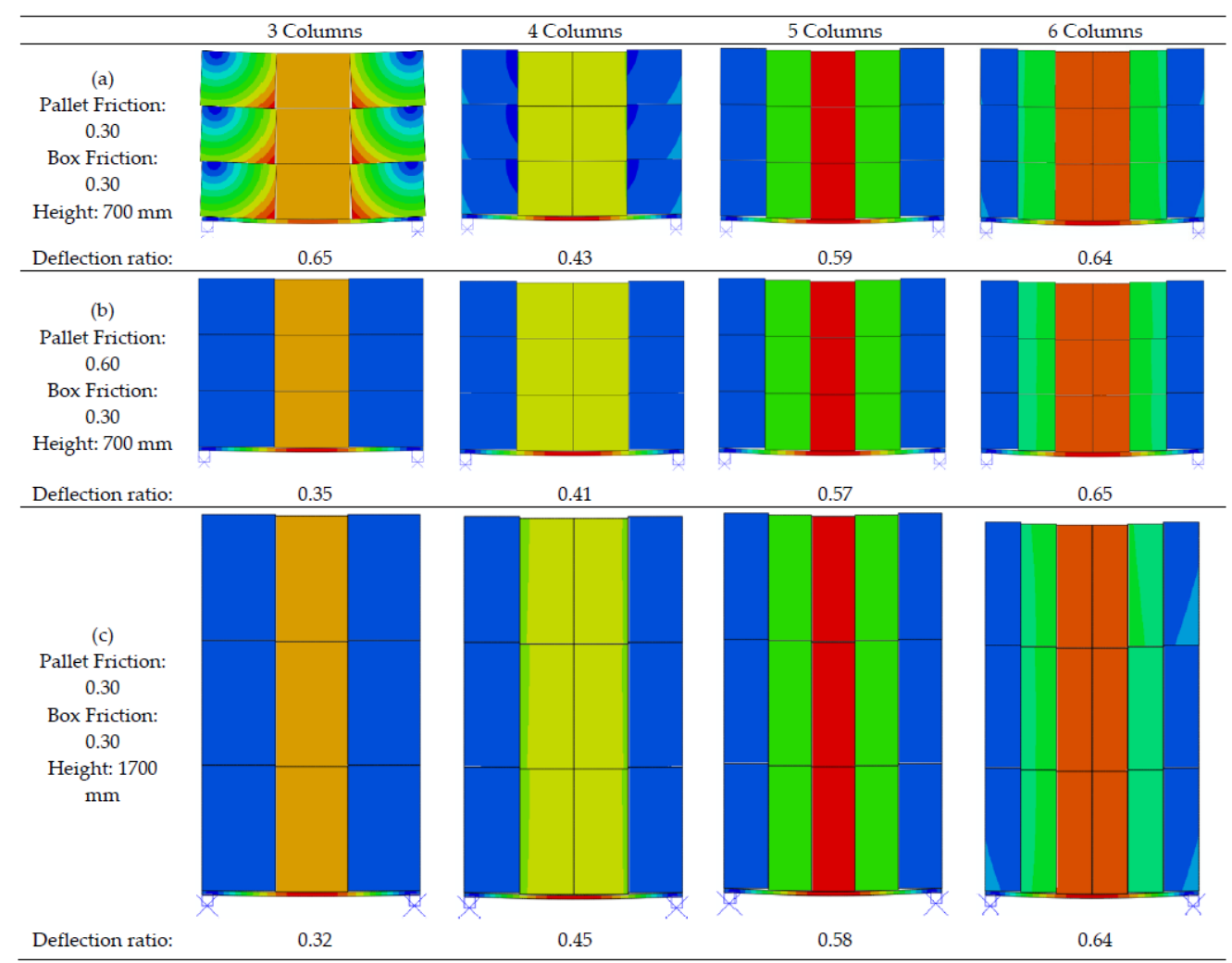

Figure 10. Finite element model simulations for 3, 4, 5, and 6 columns and three combinations of payload height and pallet and box friction coefficients. (a) Low pallet friction with short payload height; (b) high pallet friction with tall payload height; and (c) low pallet friction with tall payload height. Colors shown represent displacement $(\mathrm{U})$. Blue equals no movement, red equals large displacements. 


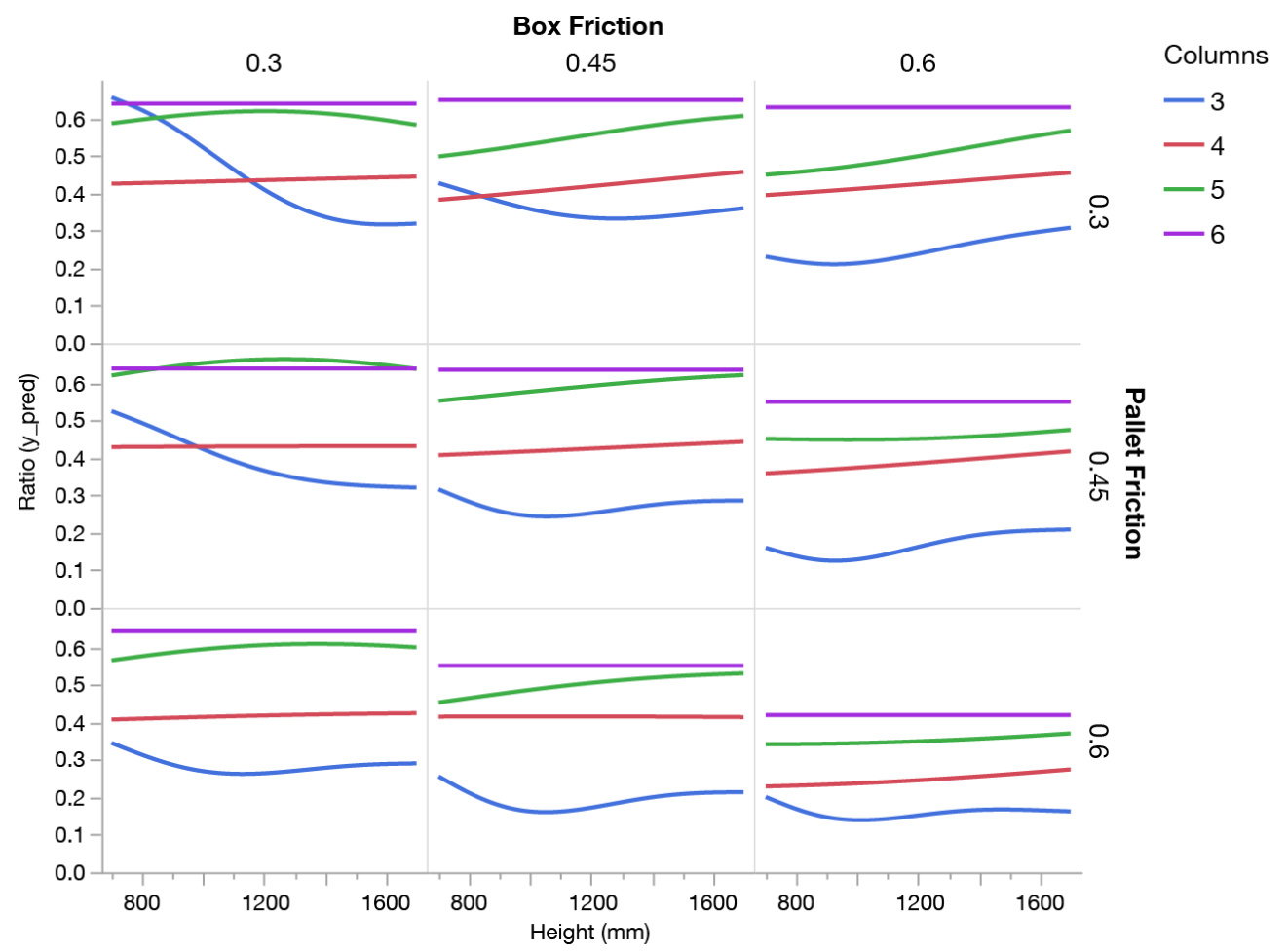

Figure 11. Effect of payload height $(\mathrm{mm})$ on board bending ratio by pallet friction, box friction, and number of columns.

\subsubsection{Effect of the Pallet Friction Coefficient on the Bending Ratio of a Board}

As can be observed in the results (Figure 12), there was an inverse relationship between the deflection ratio of the board and the pallet $\mathrm{CoF}$ for most scenarios studied. When the friction of the pallet deck increased, the bending of the board decreased. This trend has the potential to influence the design of plastic pallets. Pallets' safe load carrying capacities can be determined by finding the maximum deflection for safe handling or determining the load at which certain pallet components begin to fail $[30,31]$. Plastic pallets, given the commonly low stiffness of their structures, tend to have a maximum carrying capacity determined by their bending level under load. Affecting the resultant bending of the boards by simply increasing the friction can potentially increase the carrying capacity of a pallet. As with other factors, the interactions between the number of columns, payload height, and box friction determine the resulting effects and, therefore, it all must be studied as a system. However, unit loads carrying packages with low friction levels, such as those equivalents to returnable plastic containers (RPC), did not present such changes in board deflection, except in the case of larger boxes.

The effect of pallet friction can be observed for commonly used unit load scenarios. Take a unit load, supported on a $1219 \mathrm{~mm} \times 1016 \mathrm{~mm}$ pallet, containing $340 \mathrm{~mm} \times 250 \mathrm{~mm}$ $\times 400 \mathrm{~mm}$ corrugated boxes made of kraft paper (with an average box friction of 0.45 ), and stacked three high (having $1200 \mathrm{~mm}$ in total height). In this scenario, increasing the frictional forces by going from a pallet friction coefficient of 0.30 to 0.60 can decrease the bending response by $48 \%$. Keeping the same characteristics but using smaller boxes, $170 \mathrm{~mm} \times 254 \mathrm{~mm} \times 400 \mathrm{~mm}$ (in six columns), and increasing the pallet friction coefficient at the same rate, only decreases the bending response by $15 \%$.

\subsubsection{Effect of the Package Friction Coefficients on the Bending Ratio of a Board}

The friction coefficient of the packages was observed to be a factor that when increased, tended to reduce the bending response of the boards. The rate of change was more pronounced for larger boxes when there was a larger contact area between the boxes. This can be clearly observed in Figure 13. Furthermore, the friction coefficient for the 
packages were modeled differently for the horizontal and the vertical box surfaces. These components do not affect the bending response equally. Increasing the friction properties of the vertical package surfaces generated a reduction in the bending of the boards for most of the studied scenarios (Figure 14). Alternatively, changes on the frictional properties of the horizontal box surfaces only generated a change in board deflection for unit loads with large boxes (Figure 15). As seen in Figure 10a, the unit load with three columns presented a rotational motion of the boxes. Increasing the horizontal friction between boxes reduced this motion and affected the resulting deflection by decreasing it. Unit loads where the aspect ratio or other factors already prevented rotational motion were not affected by changes in the horizontal CoFs.

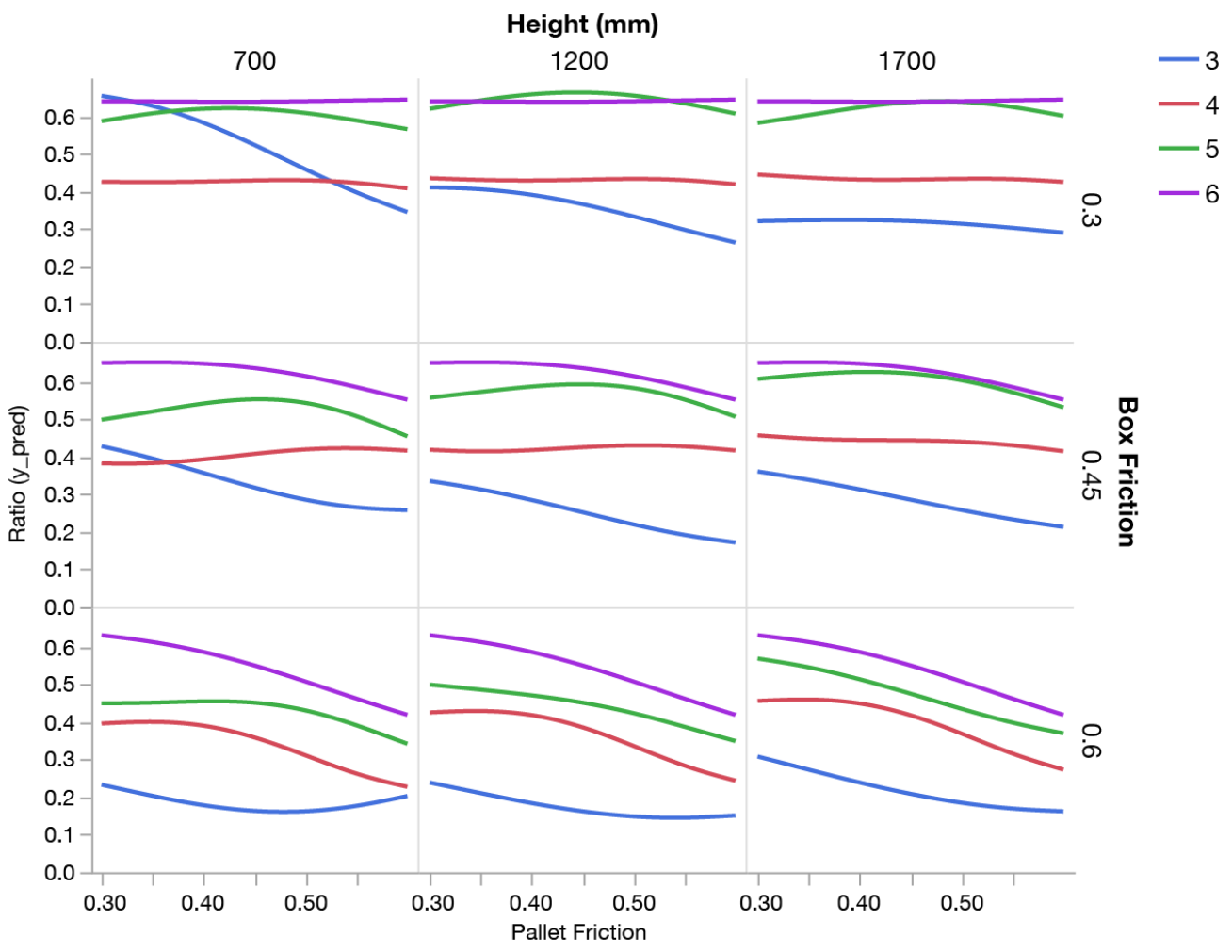

Figure 12. Effect of pallet friction coefficient on board bending ratio by payload height (mm), box friction, and number of columns.

The effect of changes in package friction coefficients can be observed for a commonly used unit load scenario. The unit load is supported on a $1200 \mathrm{~mm} \times 1000 \mathrm{~mm}$ wooden pallet ( 0.45 pallet friction) and contains $340 \mathrm{~mm} \times 250 \mathrm{~mm} \times 400 \mathrm{~mm}$ corrugated boxes made of kraft paper (average box friction of 0.45 ) that are stacked three high (1200 $\mathrm{mm}$ total height). By changing the friction of the packages on the vertical surfaces from a coefficient of 0.30 to 0.60 , while keeping the horizontal friction fixed at 0.45 , it decreases the experienced deflection by $50.4 \%$. The same scenario but with smaller $170 \mathrm{~mm} \times 125 \mathrm{~mm} \times 400 \mathrm{~mm}$ corrugated boxes (in six columns) generated a deflection reduction of only $15 \%$. Alternatively, fixing the vertical friction at 0.45 but increasing the horizontal friction coefficient from 0.30 to 0.60 can reduce the deflection by $22.1 \%$ for large boxes but does not generate any significant change in unit loads carrying small boxes.

A feature that could impact the overall effect of package friction on the bending of a unit load is the application of containment mechanisms. Methods such as stretch wrapping can restrain the boxes and prevent any rotation or displacement. The increased unitizing forces increase the overall load bridging effect and could potentially reduce the deflection experienced by the unit load. By not considering stretch wrapping or other containment methods commonly utilized, this model provides a conservative estimation of the load 
bridging effect. Further refinements can be developed in order to take into account all of the many possible modifications available for unit loads.

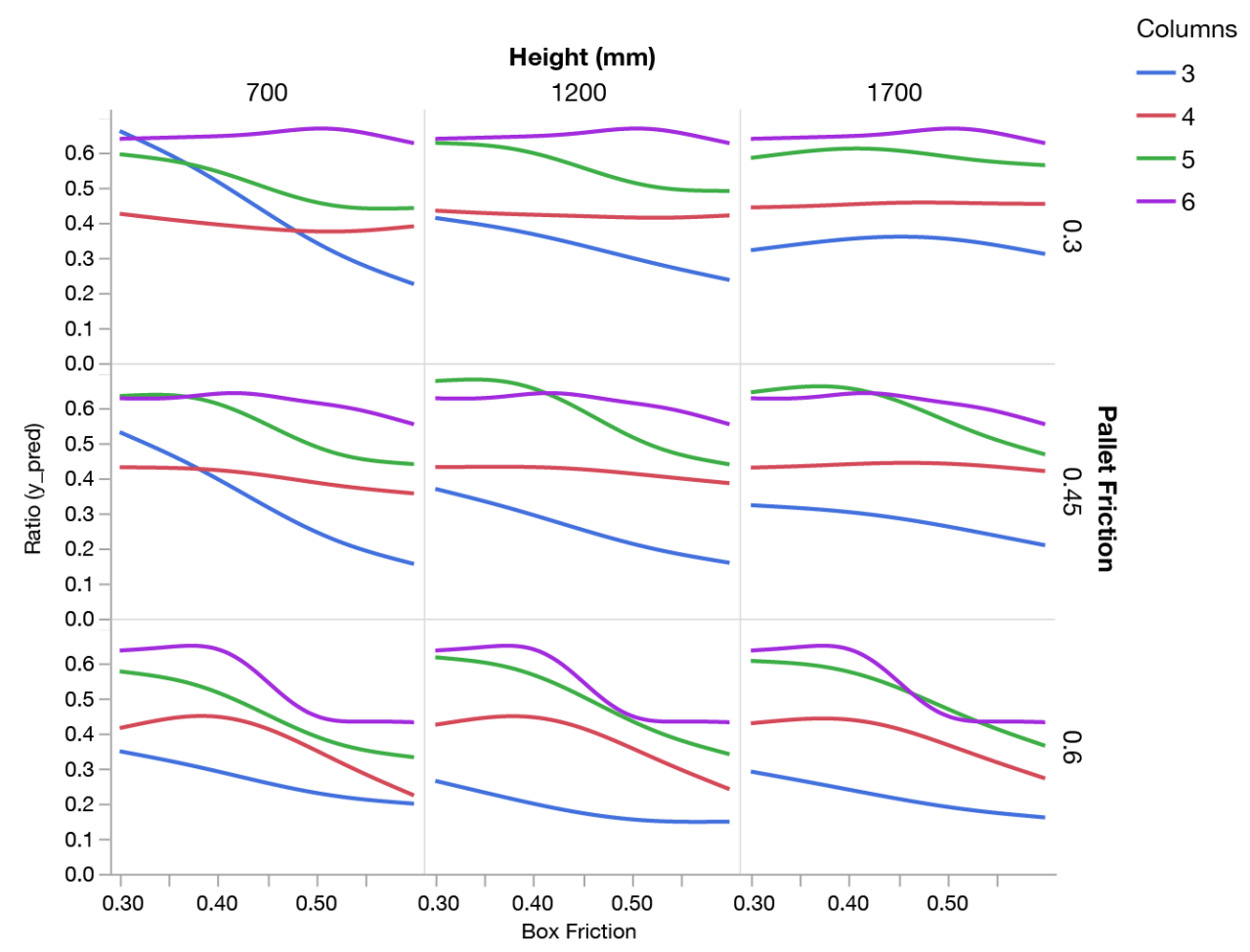

Figure 13. Effect of the friction coefficient of packages on board bending ratio by pallet friction, payload height $(\mathrm{mm})$, and number of columns.

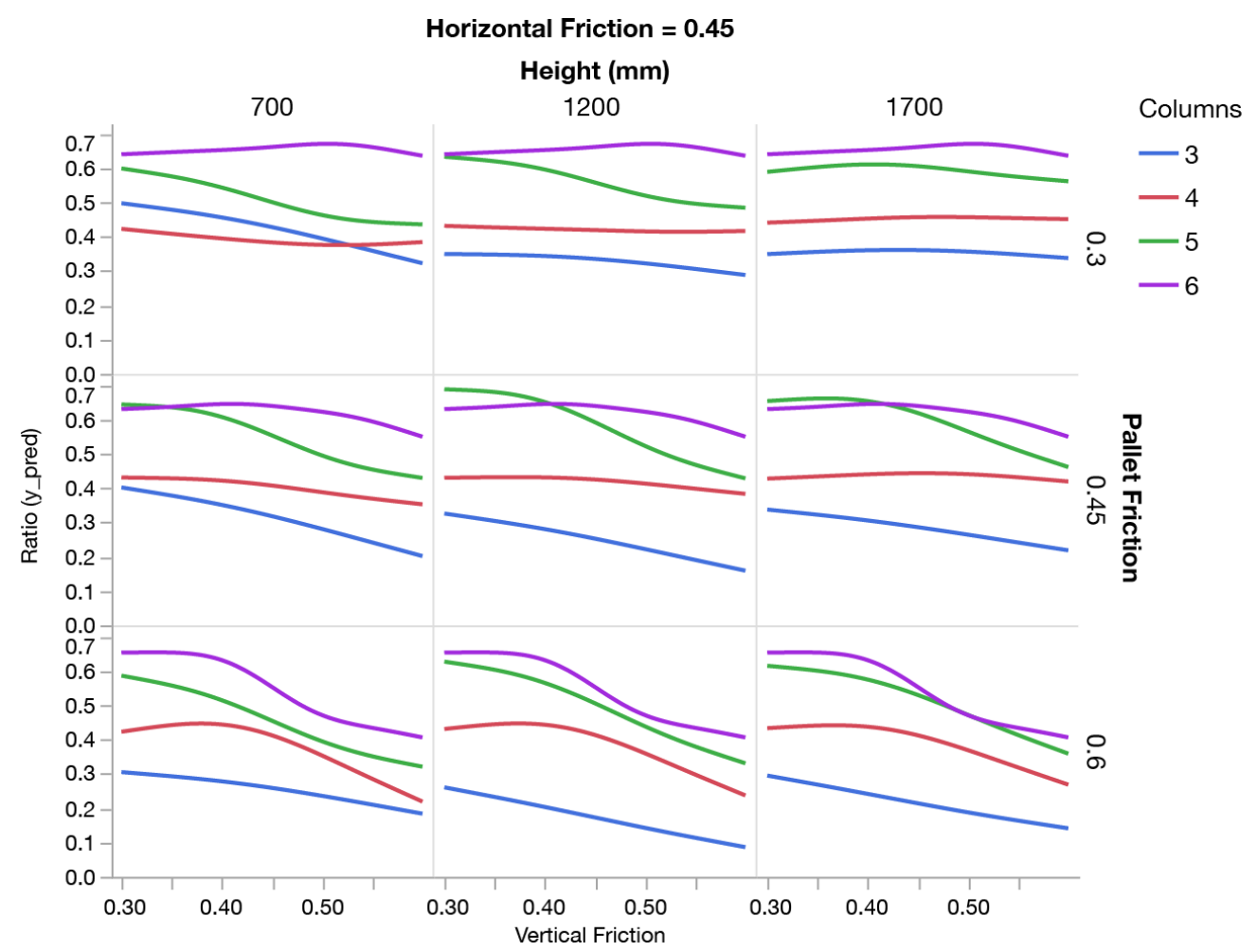

Figure 14. Effect of the friction coefficient of the vertical surface of the packages on board bending ratio by pallet friction, payload height $(\mathrm{mm})$, and number of columns, with a fixed coefficient of friction of the horizontal surface of 0.45 . 


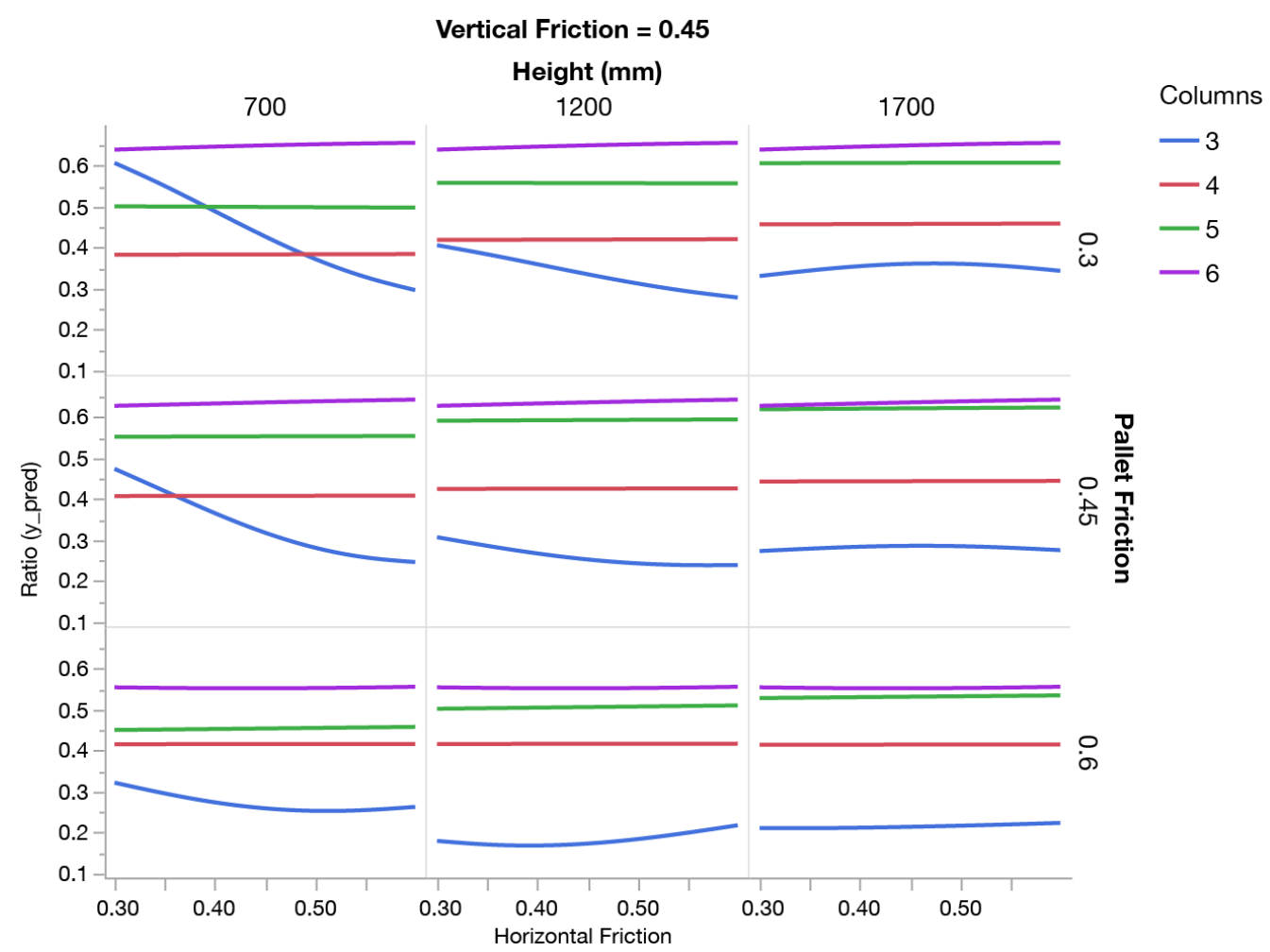

Figure 15. Effect of the friction coefficient of the horizontal surface of the packages on board bending ratio by pallet friction, payload height $(\mathrm{mm})$, and number of columns, with a fixed coefficient of friction of the vertical surface of 0.45 .

\subsection{Discussion on the Factor Interactions}

After conducting the analysis for the individual factors that influence the load bridging effect, it was evident that the existent interactions between the factors increased the complexity of the trends of the response. Traditional approaches to packaging design have focused on simple adjustment factors for specific characteristics, such as reducing box strength by a certain percent due to environmental conditions. This simplified approach, although useful for dissemination purposes, cannot be applied to the unit load development process. Some factors presented certain trends for common conditions, but when the values of other factors were modified, the trend changed. Due to the complexity of these interactions, it is not reliable to propose individual adjustment factors for each variable that could estimate the effects of load bridging. To predict the load bridging effect, a simplified model is required to calculate the resulting adjustment. The Gaussian process model developed fulfils the expectations of an approachable model that can be utilized in everyday scenarios as part of the unit load design process.

\subsection{Model Limitations}

The model here presented offers a new tool for unit load designers and researchers. It is of utmost importance to summarize the limitations of the research. In the development of the finite element model of the unit load segment, a board was used as a pallet analog. The study here presented does not consider the effect of different pallet designs, such as using block or stringer pallets, or the effects of specific pallet components. The approach selected for the study was to limit the results exclusively to the effects of the changes in the payload. In order to properly apply the developed model, researchers and users must conduct a subsequent step of evaluating the response on the specific pallet being utilized by considering the model results as one more input in the pallet design process.

Time-dependent material properties, such as creep of the pallet analog for extended periods under load, were not considered. Although pallets in warehouse storage will 
experience creep effects, it is not considered that it will change the factor significance and, overall, the main conclusions from the study.

The simplified load bridging model developed using the Gaussian process regression is limited to the ranges of values where each of the variables was validated, be them significant or non-significant factors in the payload characteristics. Although unit loads outside of these ranges commonly exist, they are not considered for the prediction properties of the model. Users must carefully evaluate these limitations before considering the results in the unit load design process.

\subsection{Model Implications and Wider Adoption Potential}

The developed model is capable of predicting accurately the bending response change of a pallet segment when the payload characteristics are modified. This model and the characterization of the effects that influence load bridging are capable of providing a valuable input to packaging engineers and designers. Such a wide and in-depth analysis of how the payload characteristics affect pallet bending was not possible to produce without the models presented here. In the past, in order to investigate the effect of any of the aforementioned factors, researchers needed to physically build a unit load, conduct laboratory testing, and compare the different results. This process requires extensive cost and monetary investment. Researchers and designers can now evaluate the effect that design decisions, such as making a unit load taller or using a pallet with a higher friction coefficient, can have in the pallet performance. The utilization of this methodology can streamline the packaging design process and allow for engineers to better consider the pallet and packages interactions to create more efficient systems.

The model developed presents an opportunity to improve the pallet and unit load design methodology. Accounting for the factors identified can allow designers to select potentially problematic unit loads and further investigate.

The results presented provide a guideline towards the change in trends of pallet deflection as payload configuration is modified. It is not the intent of the author to directly modify the safe carrying capacity of pallets. Pallet designs must be properly verified by the currently accepted methodologies. This model allows for the identification of payloads that can potentially generate larger deformation. Pallet designs must be tested with such payloads.

\section{Conclusions}

After the detailed study and screening of those factors significantly affecting load bridging and the subsequent development of a Gaussian process model, the following can be concluded:

- The number of columns in a unit load, the height of the payload, the friction coefficients of the payload's contact with the pallet deck, and the contact friction between packages were all found to be significant factors influencing the bending response of pallet analogs loaded with stacked boxes.

- The Gaussian process model can act as a surrogate model for the finite element simulation with a prediction error of five percentage points of the estimated deflection ratio.

- Aside from the significance of each studied factor, the interactions between them were found to be of high relevance to the study of load bridging. Load bridging on unit loads must be studied as a system, where variations in any characteristic will potentially influence its effect on the bending response of the remaining factors.

- The number of columns in a unit load affects the bending response. Increased package size reduces unit load bending in most scenarios, but columns' interactions with friction forces and payload height can cause an opposite change in deflection.

- Change in payload height translates to a change in the bending of the boards when supporting large boxes with low payload friction. The deflection of unit loads with smaller boxes tends not to be affected by payload height. 
- Pallet top deck friction can influence the bending response of certain unit loads, providing a potentially simple method to improve pallet performance.

- The frictional forces of the packages significantly influence the bending responses of the pallet segments, but the addition of containment methods could potentially restrict this slipping behavior. This shows that containment could limit the effect of package friction on unit load deflection.

The research project also identified that due to the complexity of the factor interactions, a simple individual adjustment factor for the load bridging effect of the various unit load factors is not feasible. Therefore, to predict the load bridging effect for unit loads, a simplified model that could be applied to everyday scenarios is required, increasing the potential applications of the Gaussian process model.

Author Contributions: E.M. and L.H. research conceptualization. E.M. Factor screening and Gaussian process model development, data collection, experimentation and writing. E.M. and L.H. data analysis collaboration. This research project was conducted under the supervision of L.H. All authors have read and agreed to the published version of the manuscript.

Funding: The research was financially supported by the Industrial Affiliate Program of the Center for Packaging and Unit Load Design at Virginia Tech.

Data Availability Statement: The data presented in this study are available on request from the corresponding author.

Conflicts of Interest: The authors declare no conflict of interest.

\section{References}

1. Research and Markets. Pallet Market: Global Industry Trends, Share, Size, Growth, Opportunity and Forecast 2021-2026. Research and Markets, June 2019. Available online: https:/ / www.researchandmarkets.com/reports/5330942 (accessed on 15 August 2019).

2. Twede, D.; Selke, S.E.M.; Kamdem, D.-P.; Shires, D. Cartons, Crates and Corrugated Board: Handbook of Paper and Wood Packaging Technology, 2nd ed.; DEStech Publications, Inc.: Lancaster, PA, USA, 2014.

3. Quesenberry, C.; Horvath, L.; Bouldin, J.; White, M.S. The effect of pallet top deck stiffness on the compression strength of asymmetrically supported corrugated boxes. Packag. Technol. Sci. 2020, 33, 547-558. [CrossRef]

4. Kellicut, K.Q. Effect of contents and load bearing surface on compressive strength and stacking life of corrugated containers. Tappi 1963, 46, 151A-154A.

5. Monaghan, J.; Marcondes, J. Technical Notes: Overhang and Pallet Gap Effects on the Performance of Corrugated Fiberboard Boxes. Trans. ASAE 1992, 35, 1945-1947. [CrossRef]

6. Baker, M. Effect of Pallet Deckboard Stiffness and Unit Load Factors on Corrugated Box Compression Strength. Ph.D. Thesis, Virginia Tech, Blacksburg, VA, USA, 12 February 2016.

7. Fagan, B. Load-Support Conditions and Computerized Test Apparatus for Wood Pallets. Master's Thesis, Virginia Tech, Blacksburg, VA, USA, 5 November 1982.

8. Loferski, J.R. A Reliability Based Design Procedure for Wood Pallets. Ph.D. Thesis, Virginia Tech, Blacksburg, VA, USA, 7 June 1985.

9. Hamner, P.; White, M. How to Design Around a Unit Load. Pallet Enterprise. Magazine 2005, 11, 40-42.

10. Wallin, W.B. Analysis for Safe Load and Deflection for Wooden Pallets and Related Structures; Report; Northeastern Forest Experiment Station, Forestry Sciences Laboratory: Princeton, WV, USA, 1979.

11. Morrissette, S.M.; Horvath, L.; Delack, K. Investigation into the load bridging effect for block class pallets as a function of package size and pallet stiffness. Packag. Technol. Sci. 2021, 34, 51-69. [CrossRef]

12. Clayton, A.P.; Horvath, L.; Bouldin, J.; Gething, B. Investigation of the effect of column stacked corrugated boxes on load bridging using partial four-way stringer class wooden pallets. Packag. Technol. Sci. 2019, 32, 423-439. [CrossRef]

13. Molina, E.; Horvath, L.; White, M.S. Investigation of pallet stacking pattern on unit load bridging. Packag. Technol. Sci. 2018, 31, 653-663. [CrossRef]

14. Collie, S.T. Laboratory Verification of Pallet Design Procedures. Master's Thesis, Virginia Tech, Blacksburg, VA, USA, 14 June 1984.

15. Park, J. Investigation of Fundamental Relationships to Improve the Sustainability of Unit Loads. Ph.D. Thesis, Virginia Tech, Blacksburg, VA, USA, 1 May 2015.

16. Park, J.; Horvath, L.; White, M.S.; Phanthanousy, S.; Araman, P.; Bush, R.J. The Influence of Package Size and Flute Type of Corrugated Boxes on Load Bridging in Unit Loads. Packag. Technol. Sci. 2017, 30, 33-43. [CrossRef]

17. Phanthanousy, S. The Effect of the Stiffness of Unit Load Components on Pallet Deflection and Box Compression Strength. Master's Thesis, Virginia Tech, Blacksburg, VA, USA, 2 May 2017. 
18. Yoo, J. Modeling Compressive Stress Distributions at the Interface between a Pallet Deck and Distribution Packaging. Ph.D. Thesis, Virginia Tech, Blacksburg, VA, USA, 8 September 2011.

19. Han, J.; White, M.; Hamner, P. Development of a Finite Element Model of Pallet Deformation and Compressive Stresses on Packaging within Pallet Loads. J. Appl. Packag. Res. 2007, 1, 149-162.

20. Molina, E.; Horvath, L.; West, R. Development of a Friction-Driven Finite Element Model to Simulate the Load Bridging Effect of Unit Loads Stored in Warehouse Racks. Appl. Sci. 2021, 11, 3029. [CrossRef]

21. Keprate, A.; Ratnayake, R.M.C.; Sankararaman, S. Experimental Validation of the Adaptive Gaussian Process Regression Model Used for Prediction of Stress Intensity Factor as an Alternative to Finite Element Method. J. Offshore Mech. Arct. Eng. 2019, 141, 1-11. [CrossRef]

22. Maatouk, H.; Bay, X. Gaussian Process Emulators for Computer Experiments with Inequality Constraints. Math. Geol. 2017, 49,557-582. [CrossRef]

23. Jones, B.; Johnson, R.T. Design and analysis for the Gaussian process model. Qual. Reliab. Eng. Int. 2009, 25, 515-524. [CrossRef]

24. Vasudevan, S.; Ramos, F.; Nettleton, E.; Durrant-Whyte, H. Gaussian process modeling of large-scale terrain. J. Field Robot. 2009, 26, 812-840. [CrossRef]

25. Daud, H.; Aris, M.M.; Noh, K.M.; Dass, S. A Novel Methodology for Hydrocarbon Depth Prediction in Seabed Logging: Gaussian Process-Based Inverse Modeling of Electromagnetic Data. Appl. Sci. 2021, 11, 1492. [CrossRef]

26. Huang, H.; Qin, A.; Mao, H.; Fu, J.; Huang, Z.; Yang, Y.; Li, X.; Huang, H. The Prediction Method on the Early Failure of Hydropower Units Based on Gaussian Process Regression Driven by Monitoring Data. Appl. Sci. 2020, 11, 153. [CrossRef]

27. Rong, Y.; Shen, Z.-J.; Yano, C.A. Cheaper by the pallet? Multi-item procurement with standard batch sizes. IIE Trans. 2012, 44, 405-418. [CrossRef]

28. O'Dell, R.; Clarke, J.W.; White, M.S. Relationship of friction characteristics and pallet performance. Va. Tech. Cent. Unit Load Des. 1998, 1, 1-20.

29. Altuglas International. Plexiglass General Information and Physical Properties. 2006. Available online: http://www. plexiglas.com/export/sites/plexiglas/.content/medias/downloads/sheet-docs/plexiglas-general-information-and-physicalproperties.pdf (accessed on 28 May 2019).

30. ISO. ISO 8611-1:2011(E) Pallets for Materials Handling_Flat Pallets. 2011. Available online: https://www.iso.org/standard/50 114.html (accessed on 26 October 2021).

31. ASTM D-1185. Standard Test Methods for Pallets and Related Structures Employed in Materials Handling and Shipping; ASTM: West Conshohocken, PA, USA, 2009; Published online. [CrossRef] 